UNIVERSIDADE DE SÃO PAULO

FACULDADE DE MEDICINA DE RIBEIRÃO PRETO

DEPARTAMENTO DE GINECOLOGIA E OBSTETRÍCIA

DANIELA ALVES MALZONE LOTT

Validação e tradução do questionário UFS-QOL

para a língua portuguesa 


\title{
Validação e tradução do questionário UFS-QOL para a língua portuguesa
}

\author{
Dissertação apresentada à Faculdade de Medicina de Ribeirão Preto da \\ Universidade de São Paulo para obtenção do título de Mestre em \\ Ciências Médicas. \\ Área de concentração: Ginecologia e Obstetrícia \\ Opção: Tocoginecologia \\ Orientador: Prof. Dr. Luiz Gustavo Oliveira Brito
}


AUTORIZO A REPRODUÇÃO E DIVULGAÇÃO TOTAL OU PARCIAL DESTE TRABALHO, POR QUALQUER MEIO CONVENCIONAL OU ELETRÔNICO, PARA FINS DE ESTUDO E PESQUISA, DESDE QUE CITADA A FONTE.

FICHA CATALOGRÁFICA

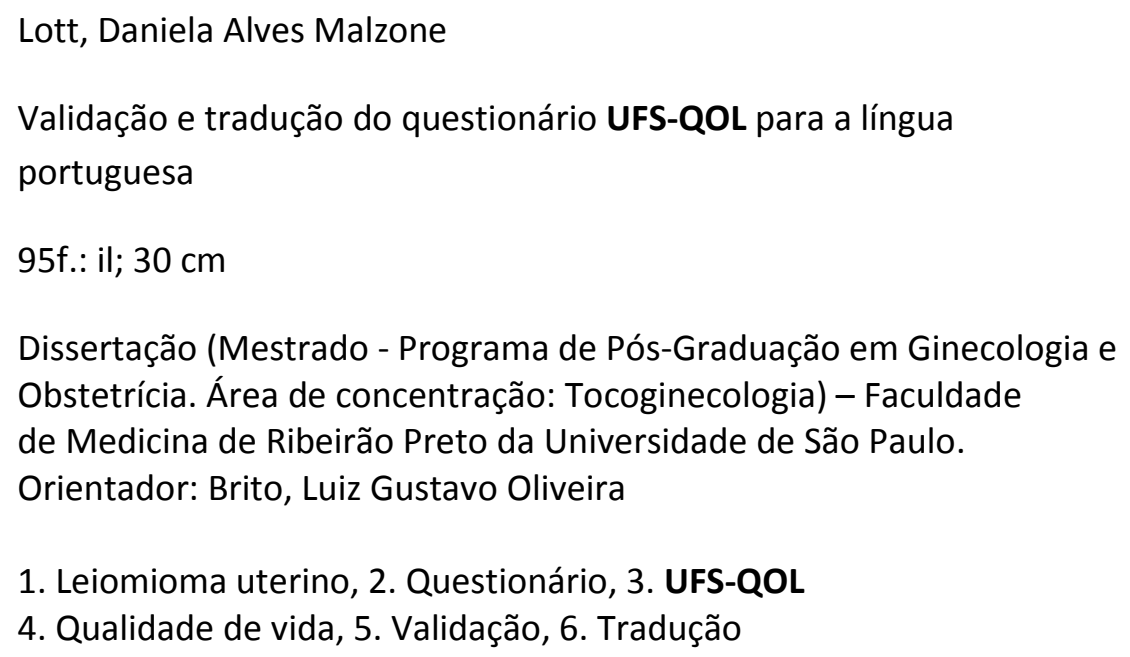

1. Leiomioma uterino, 2. Questionário, 3. UFS-QOL

4. Qualidade de vida, 5. Validação, 6. Tradução 
DANIELA ALVES MALZONE LOTT

Validação e tradução do questionário UFS-QOL para a língua portuguesa

Dissertação de Mestrado apresentada ao Programa de Pós Graduação da Faculdade de Medicina de Ribeirão Preto da Universidade de São Paulo para obtenção do título de Mestre em Ciências Médicas.

Área de concentração: Tocoginecologia

Aprovado em:

Banca Examinadora

Prof. Dr. Luiz Gustavo Oliveira Brito

Orientador - FMRP - USP Assinatura:

Prof. Dr. Julio Cesar Rosa e Silva

Instituição: FMRP-USP Assinatura:

Profa. Dra. Ilza Maria Urbano Monteiro

Instituição: UNICAMP Assinatura: 
"Vive de tal forma que deixes pegadas luminosas no caminho percorrido, como estrelas apontando o rumo da felicidade e não deixes ninguém afastar-se de ti sem que leve um traço de bondade ou um sinal de paz da tua vida".

Joanna de Ângelis 


\section{DEDICATÓRIA}

Aos meus amores incondicionais: meu marido André Henrique e meus filhos Laura Helena e Mateus Henrique. 


\section{AGRADECIMENTOS}

A Deus por me dar forças e não me permitir desisti ...

Aos meus pais Silvio e Rosalina por me proporcionarem os estudos e me ensinarem os valores morais que me tornaram a pessoa que eu sou. Amo vocês!

Ao meu irmão Silvio Henrique por se orgulhar de mim sempre.

Ao meu orientador Prof. Dr. Luiz Gustavo Oliveira Brito pela paciência, pelo incentivo e, principalmente, pela crença em minha capacidade.

Aos meus amigos Maurício Kobayashi, Ana Carolina Calderon e Priscila Feitosa pelo amor, pela amizade, pelas horas de conversa e pelo incentivo.

À Dra Mariana Arouca pela ajuda na coleta dos dados e pela amizade.

Ao querido amigo Dr. Pedro Magnani pelos ensinamentos e pelo incentivo.

Finalmente, agradeço aos meus sogros Gilberto e Nympha, por cuidarem dos meus pequenos enquanto estava trabalhando na dissertação e também pelo apoio. 


\section{RESUMO}

\section{LOTT, D.A.M. Validação e tradução do questionário UFS-QOL para a língua portuguesa.}

2016. 95f. Dissertação (Mestrado) - Faculdade de Medicina de Ribeirão Preto, Universidade de São Paulo, Ribeirão Preto, 2016.

O leiomioma uterino é o tumor ginecológico mais comum na mulher, causando principalmente sangramento uterino anormal e dor pélvica. Existe apenas um questionário que avalia a qualidade de vida de mulheres com esta doença, o Uterine Fibroid Symptom and Quality of Life (UFS-QOL), porém somente na língua inglesa. Dessa forma, objetivamos traduzir e validar culturalmente o questionário UFS-QOL para mulheres brasileiras. Realizamos um estudo transversal no Departamento de Ginecologia e Obstetrícia da Faculdade de Medicina de Ribeirão Preto da Universidade de São Paulo. Cento e treze pacientes portadoras de leiomioma uterino (grupo caso) e 55 pacientes-controle foram entrevistadas com o questionário UFS-QOL, após tradução e adaptação cultural. O questionário Short Form-36 foi utilizado para controle. Variáveis demográficas e psicométricas dos questionários (consistência interna, validade de construto, teste-reteste e responsividade) foram analisadas. As mulheres com leiomioma uterino apresentaram maior média de idade, IMC, peso, paridade e comorbidades do que no grupo controle $(p<0.05)$. 0 sangramento uterino anormal foi a queixa mais prevalente $(93,8 \%)$, seguida de dor pélvica $(36,3 \%)$ e compressão extrínseca $(10,6 \%)$, sendo que tais queixas apresentaram adequada validade de construto com a severidade do UFS-QOL $(p<0.05)$. O UFS-QOL apresentou adequada consistência interna com a severidade dos sintomas e com os domínios relacionados à qualidade de vida $(I C C=0.82 / 0.88)$. A validade estrutural mostrou coeficientes de correlação variando de 0,59 até 0,91. O teste-reteste não diferiu entre as subescalas do UFS-QOL. O teste-reteste não diferiu entre as subescalas do UFS-QOL. Depois do tratamento, as mulheres com leiomioma apresentaram melhora em todas as subescalas do UFS-QOL. Portanto, o questionário UFS-QOL para a língua portuguesa apresentou adequada tradução, boa consistência interna, validade de constructo, discriminatória,estrutural e responsividade, assim como adequado teste-reteste.

Palavras-chave: UFS-QOL; leiomioma; estudos de validação; tradução; qualidade de vida. 


\begin{abstract}
Lott, D.A.M. Validation and cultural translation for Brazilian Portuguese version of the Uterine Fibroid Symptom and Quality of Life (UFS-QOL) 2016 95p. Dissertation (Master's Degree) - Faculdade de Medicina de Ribeirão Preto, Universidade de São Paulo, Ribeirão Preto, 2016

Uterine fibroids (UF) is the most prevalent gynecological tumor, and common symptoms are abnormal uterine bleeding and pelvic pain. The Uterine Fibroids Symptoms and Quality of Life (UFS-QOL) is the only specific questionnaire that assesses the intensity of symptoms and quality-of-life issues for women with symptomatic UF; however, we do not have its translation in another language than English. Thus, we aimed to translate and culturally validate the UFS-QOL questionnaire for Brazilian Portuguese language. We performed a transversal study at the Department of Gynecology and Obstetrics, Ribeirão Preto School of Medicine, University of São Paulo. One hundred and thirteen patients with UF and 55 patients without UF (control group) were interviewed with the UFS-QOL questionnaire after translation and cultural adaptation; the Short-Form 36 questionnaire (SF36) was used as a control questionnaire. Demographic and psychometric variables (internal consistency, construct validity, test-retest and responsiveness) were analyzed. Women with UF presented a higher mean of age, body mass index, weight, parity and comorbidities than the control group $(p<0.05)$. The most prevalent symptoms were abnormal uterine bleeding $(93.8 \%)$, pelvic pain (36.3\%) and extrinsic compression (10.6\%) and they presented adequate construct validity with the UFS-QOL severity index $(p<0.05)$. The UFS-QOL presented good internal consistency in severity symptoms and HRQL scores (ICC $=0.82 / 0.88)$. Test-retest did not differ among all domains of the UFS-QOL questionnaire ( $p>.05)$. After treatment, women with UF presented an improvement in all UFS-QOL domains. Therefore, the UFS-QOL presented an adequate translation and cultural validation to the Brazilian Portuguese language, with good internal consistency, discriminant validity, construct validity, structural validity, test-retest and responsiveness.
\end{abstract}

Keywords: UFS-QOL; uterine leiomyoma; validation; translation; quality of life 


\section{LISTA DE TABELAS}

Tabela 1. Dados demográficos e clínicos da população em estudo

Tabela 2. Discriminante de validade dos questionários UFS-QOL e SF-36 dos grupos caso e controle

Tabela 3. Avaliação de Consistência interna- Correlação-item e Alfa de Cronbach......27

Tabela 4. Validade de construto: correlação sintomas do leiomioma uterino e os scores do UFS-QOL

Tabela 5. Responsividade das pacientes com leiomioma uterino após tratamento..... 28

Tabela 6. Teste-reteste do questionário UFS-QOL no grupo caso......

Tabela 7. Validade estrutural de todas as subescalas de qualidade de vida com a escala de severidade do UFS-QOL por uma modelagem de equação estrutural. 


\section{LISTA DE ABREVIATURAS}

$\begin{array}{ll}\text { HCFMRP - } & \text { Hospital das Clínicas da Faculdade de Medicina de Ribeirão Preto } \\ \text { UFS-QOL - } & \text { Uterine Fibroid Symptom and Quality of Life } \\ \text { ICC - } & \text { Coeficiente de correlação intraclasse } \\ \text { SF-36 - } & \text { Short-Form } 36 \\ \text { IMC - } & \text { Índice de Massa Corporal } \\ \text { QVRS - } & \text { Qualidade de Vida Relacionada à Saúde } \\ \text { USP - } & \text { Universidade de São Paulo }\end{array}$




\section{SUMÁRIO}

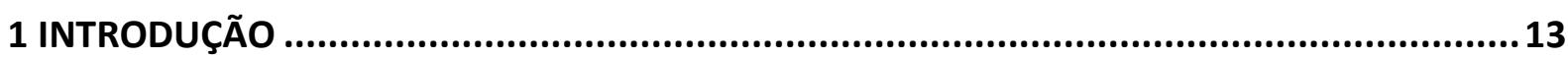

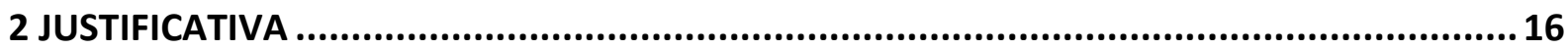

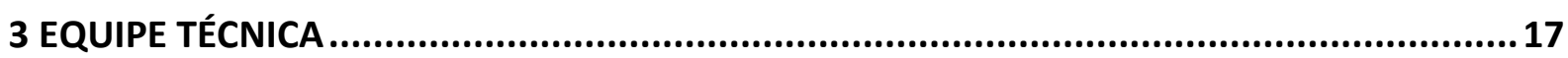

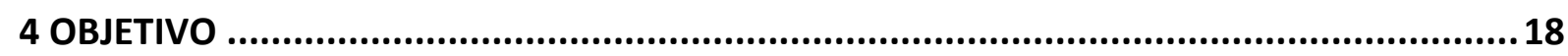

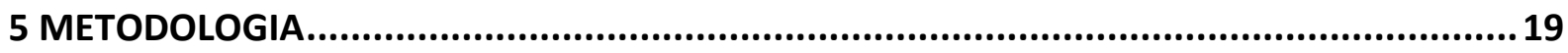

5.1 Tipo de estudo e recrutamento das pacientes................................................................. 19

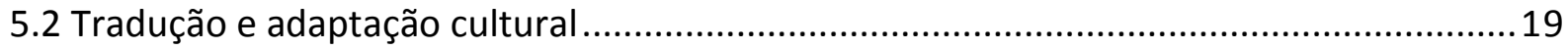

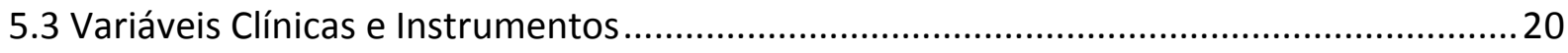

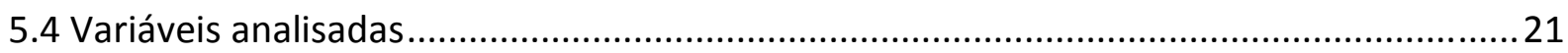

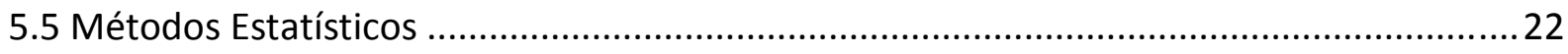

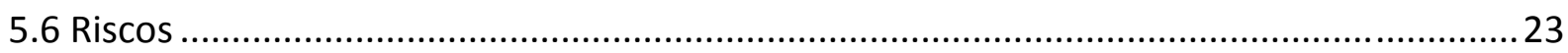

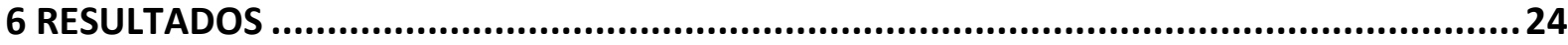

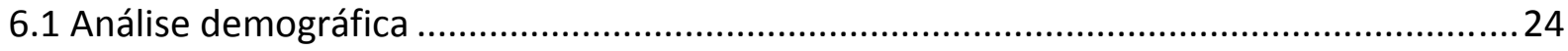

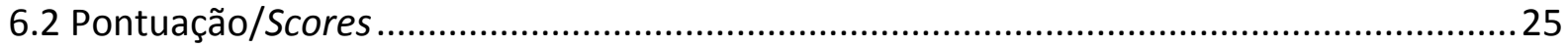

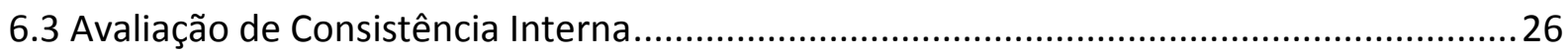

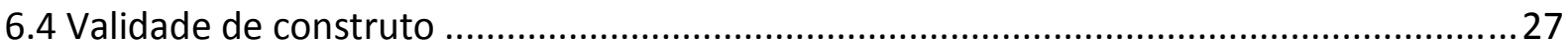

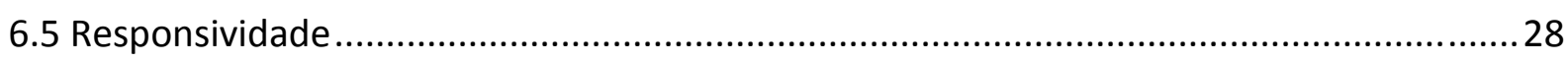

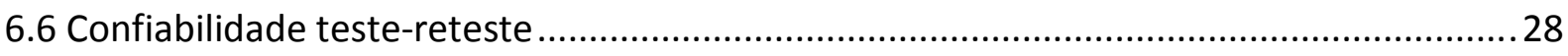

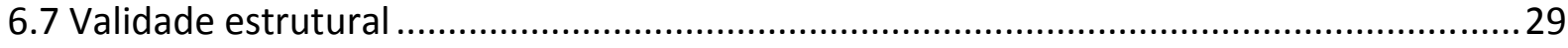

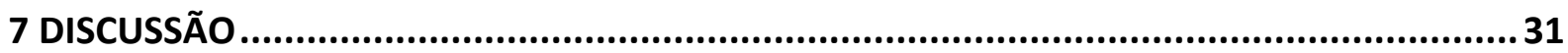

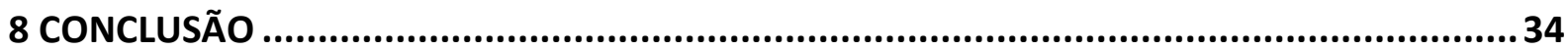

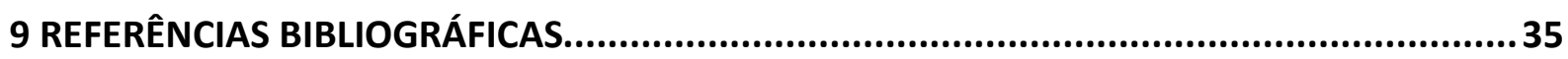




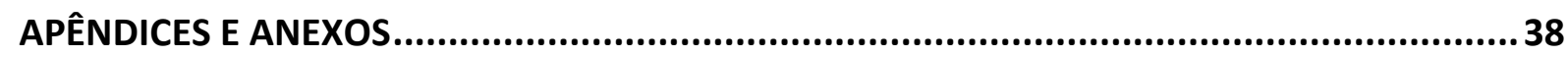

Apêndice I - Termo de Consentimento Livre e Esclarecido - grupo caso ..................................38

Apêndice II - Termo de Consentimento Livre e Esclarecido - grupo controle......................... 40

APÊNDICE III - Ficha de identificação ............................................................................ 42

APÊNDICE IV - Questionário UFS-QOL traduzido e adaptado à língua portuguesa (versão

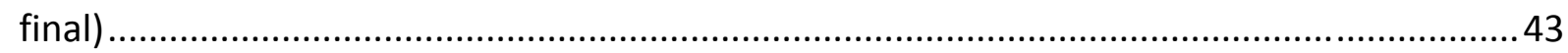

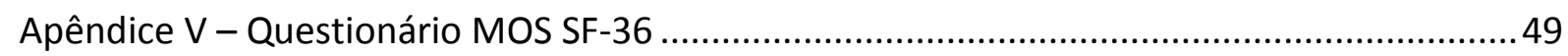

ANEXO I - Autorização para realização da Pesquisa ............................................................52

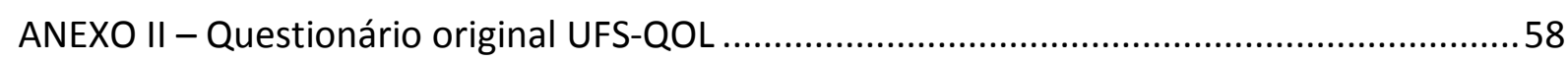

ANEXO III - Traduções juramentadas do UFS-QOL em português.........................................61

ANEXO IV - Autorização de publicação do artigo no São Paulo Medical Journal ....................69

Anexo V - Artigo aceito para publlicação no São Paulo Medical Journal ................................70

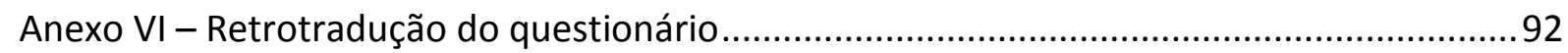




\section{INTRODUÇÃO}

O leiomioma uterino é o tumor pélvico benigno mais comum, composto por células da musculatura lisa da parede uterina, fibroblastos e é rico em matriz extracelular (STEWART,2016). É a principal causa de morbidade em mulheres na idade reprodutiva (STEWART,2016). Sessenta a oitenta por cento das mulheres apresentam esses tumores (DRAYER,2015); porém, 20 a 30\% delas apresentam sintomas tais como sangramento uterino anormal e dor pélvica (MORONI,2014). O sangramento volumoso e prolongado pode causar constrangimento social e frequentemente anemia ferropriva (STEWART,2016). Os tumores também podem aumentar o volume uterino e causar com isso sintomas de compressão extrínseca tais como: sintomas urinários (micção frequente, noctúria ou retenção urinária) e sintomas gastrointestinais (constipação e diarreia), além de distensão abdominal e dor (STEWART,2016).

O mecanismo fisiopatológico pode ser, a princípio, explicado através da sua definição tradicional, de ser um tumor monoclonal benigno das células musculares lisas que são responsivas aos hormônios esteroides e que têm características subjacentes em seu desenvolvimento de rearranjos cromossomais (STEWART,2016). Vários fatores predisponentes estão relacionados à exposição prolongada aos hormônios esteroides e/ou à predisposição genética: obesidade, nuliparidade, menarca precoce, raça negra e a idade (MORONI,2015).

Sua epidemiologia não é bem esclarecida devido a grande proporção de pacientes assintomáticas (MORONI,2015). No Brasil, não há dados precisos para essa doença, contudo, o número de histerectomias neste país foi estabilizado (DATASUS,2015), evidenciando que o manejo clínico do leiomioma continua sendo um desafio (STEWART,2015). 
Recentemente, o tratamento para o leiomioma uterino sofreu uma transformação significante. Drogas novas e mais eficientes têm sido desenvolvidas (BRITO,2013). Existem tratamentos cirúrgicos minimamente invasivos, tais como ablação endometrial e miomectomia, utilizados após falha do tratamento clínico (STEWART,2016). Ainda assim, essas terapias alternativas podem não aliviar todos os sintomas (HARDING,2008). Portanto, faz-se necessária uma forma de documentar os resultados reportados pelas pacientes a avaliação da redução dos sintomas dos leiomiomas uterinos das pacientes submetidas a tratamento (HARDING,2008). Apesar de tudo que foi descrito, ainda encontramos pesquisas que comprovam que em muitos países a histerectomia ainda é muito prevalente, em grande parte por vontade da própria paciente que, após falha do tratamento clínico, deseja melhora de sua qualidade de vida (BRITO,2013).

Um estudo observacional mostrou que as pacientes portadoras de leiomioma apresentaram um impacto negativo da doença em sua qualidade de vida (BRITO,2014). Elas mostraram limitações sociais e profissionais, medo, descrença e desencorajamento frente aos sintomas, razões que reforçam sua disposição para enfrentar uma histerectomia (BRITO,2013). Dessa forma, o impacto do leiomioma uterino na qualidade de vida relacionada à saúde (QVRS) dessas mulheres é o principal indicador para o tratamento desses tumores e o uso dos questionários pode mensurar o impacto dos sintomas e avaliar o resultado de intervenções clínicas e cirúrgicas.

Foram criados alguns questionários que não abrangiam todos os sintomas relacionados aos leiomiomas, como por exemplo o questionário para metrorragia que, além de excluir outros sintomas relacionados ao leiomioma uterino, não demonstrava mudanças significativas nos sintomas e na QVRS após certo procedimento e ainda, não incluía as 
perspectivas das pacientes e utilizava um questionário genérico sobre QVRS (HARDING,2008).

Fez-se necessária a criação de um questionário específico para leiomiomatose uterina que abrangeria os sintomas, a QVRS, além de integrar a perspectiva da paciente. Há 14 anos foi publicado um único questionário relacionado aos leiomiomas uterinos, o "Uterine Fibroid Symptom and Quality of Life" (UFS-QOL) (SPIES,2002). Outros instrumentos foram integrados ao estudo e responsividade deste questionário foi avaliada posteriormente (HARDING,2008) e sua validação ocorreu através de um estudo prospectivo não randomizado.

Desde então, a maioria dos estudos sobre o leiomioma uterino tem utilizado este questionário, que fornece documentação capaz de mensurar o impacto dos sintomas na QVRS e os resultados das intervenções.

Para o nosso conhecimento, não encontramos na literatura uma tradução ou validação cultural do UFS-QOL para a língua portuguesa. Uma simples tradução não é válida porque já é de conhecimento geral que a adaptação do questionário para a língua local é uma tarefa difícil (KOTTNER,2011). Além disso, expressões regionais podem ser incorporadas e é necessária a realização de um estudo para confirmar a validação cultural do questionário. 


\section{JUSTIFICATIVA}

O impacto dos sintomas do leiomioma na QVRS e nas atividades diárias das mulheres acometidas por este tumor são a principal indicação para o seu tratamento. 0 sangramento uterino anormal, a dor pélvica e os sintomas decorrentes da compressão extrínseca desse tumor são as principais manifestações clínicas e indicações para o seu tratamento. Existe a necessidade de avaliar estas mulheres globalmente em relação aos sintomas e ao impacto causado pelos mesmos na qualidade de vida das mesmas. No Brasil não dispomos de nenhum questionário específico para essas queixas ou tradução validada culturalmente do UFS-QOL. Portanto, fazse necessária a utilização desta ferramenta que mensura o impacto dos sintomas na QVRS e os resultados das intervenções.

Com a tradução e validação cultural do UFS-QOL para a língua portuguesa, poderemos usá-lo em pesquisas científicas e na prática clínica, permitindo uma melhor quantificação de sintomas de difícil avaliação. O impacto dos sintomas do leiomioma uterino na qualidade de vida das pacientes é uma questão muito subjetiva. Com a padronização do questionário, podemos documentar este impacto e avaliar os tratamentos. 


\section{EQUIPE TÉCNICA}

Daniela Alves Malzone Lott

Professora do Curso de Medicina da Universidade de Ribeirão Preto (UNAERP). Pós graduanda nível Mestrado do Programa de Pós-Graduação em Ginecologia e Obstetrícia da FMRP-USP

Luiz Gustavo Oliveira Brito

Médico Assistente do Setor de Cirurgia Ginecológica do HCFMRP-USP. Doutor em Medicina pela FMRP-USP. Pós-Doutor pela Universidade de Harvard. Professor do Curso de Medicina da Universidade de Ribeirão Preto (UNAERP). Pesquisador Responsável por esse estudo.

\section{Mariana Alves Fernandes Arouca}

Mestre pelo Programa de Pós-Graduação em Ginecologia e Obstetrícia da FMRP-USP. Médica Assistente do Ambulatório de Especialidades (AME) do Setor de Ginecologia do HEAB.

\section{Mayra Fernanda Sandoval Fagundes}

Aluna da FMRP-USP. Bolsista de iniciação científica da FAPESP.

\section{Pedro Sérgio Magnani}

Médico Assistente do Setor de Cirurgia Ginecológica do HCFMRP-USP. Pós-Graduando nível Doutorado Direto do Programa de Pós-Graduação em Ginecologia e Obstetrícia da FMRPUSP. 


\section{OBJETIVO}

Traduzir e adaptar culturalmente para o português o Questionário UTERINE FIBROID SYMPTOM AND QUALITY OF LIFE para a língua portuguesa. 


\section{METODOLOGIA}

\subsection{Tipo de estudo e recrutamento das pacientes}

Um estudo transversal foi realizado no ambulatório de Cirurgia Ginecológica do Hospital das Clínicas da Faculdade de Medicina de Ribeirão da Universidade de São Paulo (HCFMRP-USP) entre abril e setembro de 2015. Foram recrutadas mulheres que passaram por consultas neste ambulatório e que seriam submetidas a tratamento clínico ou cirúrgico. O grupo controle foi composto por mulheres de outros ambulatórios da clínica ginecológica do HCFMRP-USP que não apresentavam sangramento uterino anormal e dor pélvica como queixas principais. Os critérios de inclusão foram: mulheres no período reprodutivo com leiomioma uterino com queixa de sangramento uterino anormal, dor pélvica ou sensação de compressão extrínseca. Foram excluídas mulheres grávidas ou em uso de anticoagulantes ou com queixa de sangramento uterino anormal com outras causas secundárias (endometrial, ovulatória), pacientes com prejuízo cognitivo ou analfabetas. O grupo caso foi composto por 113 mulheres e o grupo controle por 55 mulheres, totalizando 168 pacientes. Tivemos 5 recusas de participação e 12 mulheres foram excluídas do estudo no período de aplicação do questionário. Todas as participantes assinaram um termo de consentimento informado e nossa pesquisa foi aprovada pelo Comitê de Ética e Pesquisa do HCFMRP-USP (processo número 531.584). Esta pesquisa foi desenvolvida de acordo com as normas éticas da Declaração de Helsinki de 1975.

\subsection{Tradução e adaptação cultural}

Depois de obtermos autorização da Sociedade Americana de Radiologia Intervencionista e do professor James Spies para traduzir e validar o questionário UFS-QOL, 
a tradução foi inicialmente realizada por duas professoras tradutoras juramentadas. Esta tradução foi avaliada por um comitê composto por três ginecologistas (L.G.O.B., D.A.M.L., M.A.F.A.) e um teste piloto foi realizado com 10 mulheres que receberam atendimento ambulatorial. Foram questionadas às pacientes sobre dificuldades de compreensão encontradas nos questionários. Algumas palavras foram adaptadas para facilitar o entendimento do entrevistado. Mudanças foram revisadas novamente pelo mesmo comitê e uma versão final foi lançada para aplicação.

Não houve padronização do modo de aplicação do questionário (entrevista oral ou auto-aplicação); entretanto, a maioria dos questionários foi auto-aplicada com a opção de pedir ajuda ao entrevistador se houver alguma dúvida de alguma questão durante a leitura.

\subsection{Variáveis Clínicas e Instrumentos}

O UFS-QOL é um instrumento específico que acessa a severidade dos sintomas (8 questões) e a QVRS das mulheres com leiomioma uterino (29 questões). Esta última subescala compreende os seguintes domínios: preocupação, atividades, energia e humor, controle, autoconsciência e função sexual (SPIES,2002). Todas as respostas têm cinco opções de escolha, de acordo com a escala de Linkert, variando de "nenhuma vez" até "todo o tempo", cujo o score é de 1 e 5. Existe uma fórmula diferenciada de cálculo do score para o domínio de severidade dos sintomas e para os demais domínios. Quanto maior o score da escala de severidade das queixas, piores os sintomas; quanto menor o score dos domínios relacionados a QVRS, pior a qualidade de vida.

O questionário SF-36 foi utilizado como controle com a finalidade de ser comparado ao UFS-QOL para calcular a validade de construto, ou seja, avaliar as correlações entre os 
questionários. Ele mensura de forma geral a QVRS usando oito domínios: vitalidade, capacidade funcional, dor, estado geral de saúde, aspectos físicos, aspectos emocionais, aspectos sociais e saúde mental (CICONELLI,1999). Itens individuais de cada subescala foram combinados para formar uma nota de subescala e ser transformada de 0 a 100 . Scores elevados indicam melhor QVRS (WARE,1992).

\subsection{Variáveis analisadas}

Foram obtidos dados demográficos tais como: idade, peso, altura, índice de massa corpórea (IMC), gestações, paridade, comorbidades. Sobre os sintomas clínicos, presença de sangramento uterino anormal (SUA), dor pélvica e sensação de compressão externa. No que diz respeito a propriedades psicométricas para mensurar questionários, as variáveis analisadas foram: consistência interna, validade de construto, teste-reteste e responsividade. A consistência interna avalia a correlação entre os itens e é determinada pelos scores das subescalas e o score total. Um valor alto indica uma melhor correlação entre os vários itens das escalas, ou seja, um ou mais itens podem medir o mesmo conceito. Valores acima de 0.70 são considerados adequados ou aceitáveis (CRONBACH,1951). A validade de construto (i.e., forma mais fundamental de validação de um instrumento pois verifica se o teste mede um atributo ou qualidade que não é operacionalmente definido, verificando se a hipótese (teste) é representante ou não dos traços latentes dos sujeitos) (TERWEE,2007) foi calculada comparando os sintomas com as respostas do questionário UFS-QOL e é considerada adequada quando se observa diferentes respostas nos grupos com e sem leiomioma uterino. Confiabilidade teste-reteste (i.e., reprodução de medidas repetidas com respostas semelhantes pelos entrevistados) é avaliada pelo Coeficiente de 
Correlação Intraclasse (ICC). Valores $\geq 0.70$ são considerados de adequada confiabilidade (GUILLEMIN,1993; MCGRAW,1996). O reteste $(n=20)$ foi realizado uma a duas semanas após a primeira aplicação do questionário. Responsividade (i.e., habilidade da medida de verificar alterações no decorrer do tempo) foi realizada através da aplicação dos testes antes e após tratamento, durante o seguimento clínico das pacientes do grupo caso. Foi realizada após 3 meses da primeira aplicação para avaliar se os scores do UFS-QOL mudaram após tratamento clínico ou cirúrgico em 44 pacientes.

\subsection{Métodos Estatísticos}

Os dados foram tabulados em planilha do Microsoft Excel (Richmond, VA, USA) e a análise estatística foi realizada através do Intercooled Stata 13.0 (College Station, TX, USA). Um nível de significância de $5 \%$ foi estipulado com todos os testes bicaudais. A análise de normalidade amostral foi realizada pelo teste de Shapiro-Wilk e uma distribuição paramétrica foi encontrada. O teste Qui-Quadrado foi utilizado para as variáveis binomiais e o teste t de Student para as variáveis contínuas. A consistência interna foi calculada pelo alfa de Crombach e correlação - item. O cálculo do poder estatístico não foi realizado devido à grande variabilidade de fórmulas sugeridas para a geração da quantidade mínima de indivíduos para determinada pesquisa que envolva validação e tradução de questionário padronizado. A consistência interna foi calculada pelo alpha de Cronbach (>0,9 excelente; 0,7 a 0,9 aceitável a boa; 0,6 a 0,7 questionável; 0,5 a 0,6 ruim; < 0,5 inaceitável) e correlação de itens. A validade estrutural foi calculada utilizando modelo de equação estrutural entre a gravidade e outras subescalas de qualidade de vida. 
Teste-reteste e responsividade foram calculados pelo teste $t$ pareado. Dados faltantes nas tabelas apresentadas não sofreram método de imputação. Nenhuma das pacientes que responderam os dois questionários finalizaram com menos de $50 \%$ das perguntas respondidas.

\subsection{Riscos}

As mulheres entrevistadas foram orientadas a interromper a coleta de dados caso surgisse algum desconforto durante a aplicação dos questionários.

A coleta e análise de dados foi realizada conforme os preceitos éticos expostos pela Comissão de Ética em Pesquisa e Ética Médica, assegurando sigilo e confidencialidade. 


\section{RESULTADOS}

Foram inclusas no estudo 168 pacientes, sendo 113 pacientes com leiomioma uterino (grupo caso) e 55 pacientes sem leiomioma uterino (grupo controle). Das 113 pacientes do grupo caso, 20 foram novamente entrevistadas após 1 a 2 semanas da primeira aplicação dos questionários, e 44 foram avaliadas após tratamento clínico ou cirúrgico.

\subsection{Análise demográfica}

Os dados demográficos estão descritos na tabela 1. Mulheres com leiomioma uterino apresentaram uma maior média de idade $(42.6 \pm 6.5$ anos; $p<.005)$, peso $(78.9 \pm 16.7 \mathrm{~kg})$, IMC $\left(30.3 \pm 6 \mathrm{~kg} / \mathrm{m}^{2} ; p=.01\right)$, paridade $(p<.005)$ e uma tendência estatística de apresentar mais comorbidades ( $53.1 \%$ vs $38.2 \% ; p=.069)$ do que o grupo controle. As doenças mais comuns do grupo caso foram hipertensão arterial sistêmica, ansiedade e distúrbios depressivos. No que diz respeito aos sintomas clínicos, SUA foi o mais prevalente $(93,8 \%)$, seguido da dor pélvica (36,3\%) e compressão extrínseca $(10,6 \%)$. 
Tabela 1 - Características demográficas e clínicas das pacientes estudadas.

\begin{tabular}{|c|c|c|c|}
\hline Variáveis & Controle $(n=55)$ & Caso $(n=113)$ & p valor \\
\hline Idade (média $\pm D P$ ) & $37.9(8.2)$ & $42.6(6.5)$ & $<0.005$ \\
\hline Gestações (mediana/alcance) & $1(0-6)$ & $2(0-6)$ & $<0.005$ \\
\hline Paridade (mediana/alcance) & $1(0-5)$ & $2(0-6)$ & $<0.005$ \\
\hline Escolaridde $(n, \%)$ & & & $<0.005$ \\
\hline $0-6$ anos & $15(27.3)$ & $44(38.9)$ & \\
\hline 7-12 anos & $21(38.2)$ & $63(55.9)$ & \\
\hline$>12$ anos & $18(32.7)$ & $3(2.6)$ & \\
\hline Não informado & $1(1.8)$ & $3(2.6)$ & \\
\hline Índice de massa corpórea (média $\pm D P$ ) & $27.7(5.8)(n=54)$ & $30.3(6.0)(n=110)$ & 0.010 \\
\hline Comorbidades(n, \%) & $21(38.18)$ & $60(53.1)$ & 0.069 \\
\hline \multicolumn{4}{|l|}{ Sintomas } \\
\hline Sangramento uterino anormal & $1(1.8)$ & $106(93.8)$ & $<0.005$ \\
\hline Dor pélvica & $3(5.5)$ & $41(36.3)$ & $<0.005$ \\
\hline Compressão extrínseca & $1(1.8)$ & $12(10.6)$ & $<0.005$ \\
\hline
\end{tabular}

\subsection{Pontuação/Scores}

A tabela 2 mostra as análises dos scores UFS-QOL e do SF-36 nos dois grupos. Todas as subescalas do UFS-QOL mostraram diferenças estatisticamente significantes entre as mulheres com leiomioma uterino e o grupo controle $(p<.05)$. As mulheres com leiomioma uterino apresentaram scores mais altos na severidade dos sintomas e scores mais baixos nas subescalas que mensuravam a qualidade de vida quando comparadas com o grupo controle. No que diz respeito aos domínios do SF-36, as mulheres com leiomioma uterino apresentaram pior qualidade de vida $(p<.05)$, com exceção do domínio vitalidade $(p=.07)$. or isso, a discriminante de validade pode ser demonstrada. 
Tabela 2 - Validade discriminante dos questionários UFS-QOL e SF-36 das pacientes com leiomioma uterino e as pacientes do grupo controle

\begin{tabular}{|c|c|c|c|}
\hline \multirow[t]{3}{*}{ Questionários } & \multicolumn{2}{|c|}{ Média (DP) } & \multirow[t]{2}{*}{ p valor } \\
\hline & Controle & Caso & \\
\hline & $(N=55)$ & $(N=113)$ & \\
\hline \multicolumn{4}{|l|}{ UFS-QOL } \\
\hline Severidade dos sintomas & $15.7(17.6)$ & $59.4(19.1)$ & $<0.001$ \\
\hline Consciência & $95.2(10.9)$ & $33.6(28.7)$ & $<0.001$ \\
\hline Atividades & $96.5(10.6)$ & $53.8(26.0)$ & $<0.001$ \\
\hline Energia/Humor & $92.9(18.6)$ & $47.3(28.5)$ & $<0.001$ \\
\hline Controle & $94.5(16.2)$ & $51.3(27.3)$ & $<0.001$ \\
\hline Autoconsciência & $94.7(16.2)$ & $49.3(25.7)$ & $<0.001$ \\
\hline Função sexual & $90.7(23.8)$ & $43.9(36.6)$ & $<0.001$ \\
\hline Score total & 361.7 (73.7) & $115.7(116.9)$ & $<0.001$ \\
\hline \multicolumn{4}{|l|}{ SF-36 } \\
\hline Funcionamento físico & $74.9(32.3)$ & $59.2(29.6)$ & 0.0021 \\
\hline Limitação por aspectos físicos & $73.2(39.0)$ & $38.3(44.9)$ & $<0.001$ \\
\hline Dor no corpo & $62.5(26.2)$ & $52.0(28.4)$ & 0.023 \\
\hline Saúde geral & $58.6(17.9)$ & $50.5(20.2)$ & 0.013 \\
\hline Vitalidade & $56.9(21.7)$ & $49.6(25.8)$ & 0.072 \\
\hline Funcionamento social & $74.8(30.7)$ & $59.9(32.0)$ & 0.003 \\
\hline Limitação por aspectos emocionais & $72.7(40.1)$ & $44.8(44.5)$ & $<0.001$ \\
\hline Saúde mental & $60.7(21.5)$ & $50.8(26.5)$ & 0.017 \\
\hline
\end{tabular}

\subsection{Avaliação de Consistência Interna}

A consistência interna foi calculada para o UFS-QOL na tabela 3 e valores acima de 0.75 foram encontrados para todas as subescalas e os scores da QVRS nos grupos caso e controle mostraram concordância adequada. Correlação-item apresentou concordância moderada na severidade dos sintomas; similarmente, no grupo caso, uma concordância moderada foi encontrada no grupo caso na severidade dos sintomas. 
Tabela 3 - Consistência Interna (ICC) e correlação item de mulheres com leiomioma uterino e o grupo controle

\begin{tabular}{|l|c|c|c|c|}
\hline UFS-QOL & & & \\
\hline & \multicolumn{2}{|c|}{ Controle (n=55) } & \multicolumn{2}{c|}{ Caso (n=113) } \\
\hline & Correlação-item & Alfa de Cronbach & Correlação-item & Alfa de Cronbach \\
\hline $\begin{array}{l}\text { Severidade dos } \\
\text { sintomas }\end{array}$ & 0.59 & 0.84 & 0.65 & 0.82 \\
\hline Consciência & 0.84 & 0.84 & 0.80 & 0.80 \\
\hline Atividades & 0.89 & 0.83 & 0.81 & 0.81 \\
\hline Energia/humor & 0.96 & 0.81 & 0.86 & 0.80 \\
\hline Controle & 0.92 & 0.82 & 0.86 & 0.80 \\
\hline Autoconsciência & 0.90 & 0.82 & 0.66 & 0.82 \\
\hline Função sexual & 0.90 & 0.80 & 0.72 & 0.81 \\
\hline Score da QVRS & 1.00 & 0.91 & 1.00 & 0.88 \\
\hline
\end{tabular}

\subsection{Validade de construto}

Validade de construto mostrou significância estatística entre a presença de sintomas e uma média mais alta no score da severidade no UFS-QOL.

Tabela 4 - Validade de Construto entre os sintomas do leiomioma uterino e o questionário

\begin{tabular}{|l|c|c|c|c|c|c|c|}
\hline & Com sintoma & \multicolumn{2}{c|}{$\begin{array}{c}\text { Sem } \\
\text { sintoma }\end{array}$} & & & \\
\hline & \multicolumn{2}{|c|}{ Média \pm DP } & & \multicolumn{2}{c|}{$\begin{array}{c}\text { Diferenças } \\
\text { médias }\end{array}$} & p-valor \\
\hline $\begin{array}{l}\text { Sangramento uterino } \\
\text { anormal }\end{array}$ & $59.57 \pm 19.92$ & & $19.67 \pm 20.10$ & -39.9 & $<0.001$ \\
\hline Dor pélvica & $60.51 \pm 20.15$ & & $39.61 \pm 28.02$ & -20.89 & & $<0.001$ \\
\hline $\begin{array}{l}\text { Compressão } \\
\text { extrínseca }\end{array}$ & $56.00 \pm 23.74$ & & $44.17 \pm 27.88$ & & -11.83 & & 0.014 \\
\hline
\end{tabular}




\subsection{Responsividade}

No que diz respeito a responsividade, todos os domínios do UFS-QOL apresentaram melhora na qualidade de vida e uma redução na severidade dos sintomas após o tratamento.

Tabela 5 - Responsividade das mulheres com leiomioma uterino após tratamento $(n=44)$

\begin{tabular}{|l|c|c|c|c|c|c|}
\hline & \multicolumn{2}{|c|}{$\begin{array}{c}\text { Antes do } \\
\text { tratamento }\end{array}$} & $\begin{array}{c}\text { Depois do } \\
\text { tratamento }\end{array}$ & & \\
\hline UFS-QOL & \multicolumn{2}{|c|}{ Média/DP } & \multicolumn{2}{c|}{$\begin{array}{c}\text { Diferença } \\
\text { médias }\end{array}$} & p-valor \\
\hline $\begin{array}{l}\text { Severidade dos } \\
\text { sintomas }\end{array}$ & $54.97(14.57)$ & & $15.05(17.91)$ & -39.91 & & $<0.005$ \\
\hline Consciência & $32.84(24.97)$ & $86.59(24.97)$ & +53.75 & & $<0.005$ \\
\hline Atividades & $57.95(24.96)$ & & $91.72(13.81)$ & +33.76 & & $<0.005$ \\
\hline Energia/humor & $50.08(28.37)$ & & $83.76(22.69)$ & +33.69 & & $<0.005$ \\
\hline Controle & $54.32(26.86)$ & & $87.61(20.50)$ & +33.29 & & $<0.005$ \\
\hline Autoconsciência & $50.95(22.68)$ & & $75.19(27.70)$ & +24.24 & & $<0.005$ \\
\hline Função sexual & $43.18(36.21)$ & & $65.91(39.19)$ & +22.72 & & $<0.005$ \\
\hline Score da QVRS & $124.42(108.26)$ & $298.09(110.96)$ & +173.68 & & $<0.005$ \\
\hline
\end{tabular}

\subsection{Confiabilidade teste-reteste}

Finalmente, não foram encontradas diferenças no teste-reteste na versão do UFS-

QOL para a língua portuguesa. 
Tabela 6 - Teste-reteste do questionário UFS-QOL no grupo caso $(n=20)$.

\begin{tabular}{|l|c|c|c|c|c|c|}
\hline & \multicolumn{2}{|c|}{ Teste } & \multicolumn{2}{c|}{ Reteste } & & \\
\hline UFS-QOL & \multicolumn{2}{|c|}{ Média (DP) } & \multicolumn{2}{c|}{ Diferença médias } & p-value \\
\hline $\begin{array}{l}\text { Severidade dos } \\
\text { sintomas }\end{array}$ & $57.19(19.35)$ & & $52.03(32.81)$ & -5.16 & & 0.453 \\
\hline Consciência & $39.5(33.34)$ & $48.25(35.37)$ & +8.75 & & 0.088 \\
\hline Atividades & $54.8(27.79)$ & & $61.79(30.35)$ & +6.96 & & 0.270 \\
\hline Energia/humor & $54.64(32.36)$ & $54.11(33.83)$ & -0.53 & & 0.929 \\
\hline Controle & $53.5(27.29)$ & & $60(32.16)$ & +6.5 & & 0.223 \\
\hline Autoconsciência & $50.83(31.75)$ & $53.33(32.82)$ & +2.5 & & 0.746 \\
\hline Função sexual & $46.25(35.14)$ & $45(39.82)$ & & -1.25 & & 0.892 \\
\hline Score da QVRS & $133.23(133.27)$ & $152.99(158.69)$ & +19.77 & & 0.452 \\
\hline
\end{tabular}

\subsection{Validade estrutural}

A análise dos coeficientes padronizados das subescalas da qualidade de vida tendo como covariável a severidade foi de 0,59 a 0,91 , como mostra a tabela 7 . A análise de covariância com severidade mostrou maior correlação com as seguintes subescalas: preocupação $(0,91)$, controle $(0,80)$ e autoconsciência $(0,81)$.

Tabela 7 - Validade estrutural de todas as subescalas de qualidade de vida com a escala de severidade do UFS-QOL por uma modelagem de equação estrutural

\begin{tabular}{|l|c|c|}
\hline $\begin{array}{l}\text { Questionário UFS-QOL (modelo da interação das subescalas da } \\
\text { qualidade de vida com a escala da severidade) }\end{array}$ & $\begin{array}{c}\text { Coeficiente } \\
\text { padronizado (Erro } \\
\text { padrão)) }\end{array}$ & Variância \\
\hline Consciência (últimos 3 meses) & $0.78(0.031)$ & 0.38 \\
\hline $\begin{array}{l}\text { Ansiedade sobre imprevisão do sangramento /duração dos } \\
\text { períodos (Q9) }\end{array}$ & $0.91(0.015)$ & 0.16 \\
\hline Manchar roupas íntimas (Q15) & $0.88(0.018)$ & 0.21 \\
\hline Manchar roupas de cama (Q22) & $0.67(0.044)$ & 0.54 \\
\hline Sentir incômodo por carregar absorventes (Q28) & $0.91(0.015)$ & 0.15 \\
\hline Manchar roupas externas (Q32) & & \\
\hline Atividades (últimos 3 meses) & & \\
\hline
\end{tabular}




\begin{tabular}{|c|c|c|}
\hline $\begin{array}{l}\text { Questionário UFS-QOL (modelo da interação das subescalas da } \\
\text { qualidade de vida com a escala da severidade) }\end{array}$ & $\begin{array}{c}\text { Coeficiente } \\
\text { padronizado (Erro } \\
\text { padrão)) }\end{array}$ & Variância \\
\hline Ansiedade sobre viagens (Q10) & $0.62(0.050)$ & 0.60 \\
\hline Interferência em atividades físicas (Q11) & $0.77(0.036)$ & 0.39 \\
\hline Diminuiu tempo com atividades físicas (Q13) & $0.73(0.041)$ & 0.45 \\
\hline Sentiu dificuldade em executar tarefas habituais (Q19) & $0.78(0.034)$ & 0.38 \\
\hline Interferiu em atividades sociais (Q20) & $0.78(0.034)$ & 0.38 \\
\hline Planejar atividades com precaução (Q27) & $0.82(0.028)$ & 0.31 \\
\hline Causou constrangimento (Q29) & $0.78(0.034)$ & 0.38 \\
\hline \multicolumn{3}{|l|}{ Energia (últimos 3 meses) } \\
\hline Sentiu cansaço (Q12) & $0.81(0.029)$ & 0.34 \\
\hline Sentiu sono ou tontura durante o dia (Q17) & $0.72(0.039)$ & 0.47 \\
\hline Sentiu tristeza, desencorajamento ou desespero (Q23) & $0.88(0.020)$ & 0.21 \\
\hline Sentiu-se deprimida ou abatida (Q24) & $0.88(0.019)$ & 0.21 \\
\hline Sentiu cansaço extremo (Q25) & $0.86(0.022)$ & 0.25 \\
\hline Sentiu irritação (Q31) & $0.83(0.025)$ & 0.29 \\
\hline Sentiu como se a energia fosse sugada do seu corpo (Q35) & $0.87(0.020)$ & 0.24 \\
\hline \multicolumn{3}{|l|}{ Controle (últimos 3 meses) } \\
\hline Sentiu como se não tivesse controle sobre sua vida (Q14) & $0.79(0.033)$ & 0.37 \\
\hline Sentiu-se menos produtiva (Q16) & $0.78(0.034)$ & 0.38 \\
\hline Preocupação com a saúde (Q26) & $0.84(0.027)$ & 0.29 \\
\hline Sentiu incerteza sobre o futuro (Q30) & $0.77(0.035)$ & 0.39 \\
\hline Sentiu como se não tivesse controle sobre sua saúde(Q34) & $0.84(0.028)$ & 0.29 \\
\hline \multicolumn{3}{|l|}{ Autoconsciência (últimos 3 meses) } \\
\hline Sensação de ganho de peso (Q18) & $0.71(0.048)$ & 0.49 \\
\hline Percepção sobre o tamanho da barriga (Q21) & $0.80(0.041)$ & 0.35 \\
\hline $\begin{array}{l}\text { Alteração do tamanho das roupas durante os períodos menstruais } \\
\text { (Q33) }\end{array}$ & $0.59(0.058)$ & 0.64 \\
\hline \multicolumn{3}{|l|}{ Função sexual (últimos 3 meses) } \\
\hline Diminuição do desejo sexual (Q36) & $0.90(0.031)$ & 0.17 \\
\hline Fizeram com que a paciente evitasse ter relações sexuais (Q37) & $0.90(0.032)$ & 0.18 \\
\hline Covariância de severidade -Preocupação & $0.91(0.018)$ & -------------- \\
\hline Covariância de severidade - Atividade & $0.79(0.036)$ & -------------- \\
\hline Covariância de severidade - Energia & $0.78(0.034)$ & --------------- \\
\hline Covariância de severidade - Controle & $0.80(0.035)$ & -------------- \\
\hline Covariância de severidade - Autoconsciência & $0.81(0.043)$ & \\
\hline Covariância de severidade - Função sexual & $0.65(0.050)$ & -------------- \\
\hline
\end{tabular}




\section{DISCUSSÃO}

Esta pesquisa mostrou que o UFS-QOL correlaciona fortemente os sintomas das mulheres com leiomioma uterino com piores scores nos domínios da QVRS e scores elevados na severidade dos sintomas, mostrando que houve impacto da doença na qualidade de vida das mulheres. Não foram encontradas diferenças no que diz respeito a ICC e não foram encontradas diferenças entre os domínios do UFS-QOL em mulheres com leiomioma uterino apesar da correlação-item ser moderada entre a severidade dos sintomas, autoconsciência e função sexual. Esses dados foram similares aos dados da pesquisa de validação realizada por Spies et al. (SPIES,2009; COYNE,2012). Além do mais, mulheres com leiomioma uterino apresentaram pior qualidade de vida quando analisadas pelo questionário SF-36, com exceção do domínio vitalidade. Isso pode assinalar que o questionário UFS-QOL está cumprindo a tarefa de discernir as mulheres com leiomioma uterino.

A confiabilidade do nosso teste-reteste foi demonstrada após o teste t pareado onde não houve diferença sistemática após o intervalo de 1 a 2 semanas para a segunda visita. Isto foi similar ao que Spies et al. (SPIES,2002) encontraram com 27 pacientes e este tamanho de amostra não foi considerado insuficiente para detectar diferenças nas características de referência. Nossa amostragem total é maior do que a apresentada na primeira publicação deste questionário e nós também concordamos com Spies et al. (SPIES,2002) que mulheres com leiomioma uterino apresentam características epidemiológicas que dificultariam a criação de um grupo controle similar devido a esta alta prevalência.

Além disso, a versão do UFS-QOL para a língua portuguesa também tem demonstrado responsividade para mudança na QVRS entre mulheres tratadas com 
medicações ou cirurgia, com mudança da média dos scores maior do que 20 pontos para todas as subescalas. Apesar de 40 pacientes serem incluídas, estes dados foram respaldados por Harding et al. (HARDING,2008) que analisou 102 pacientes tratadas com ultrassom focado guiado por ressonância para leiomioma uterino e concluiu que o questionário é sensível às mudanças na percepção da paciente no que diz respeito a severidade dos sintomas e na QVRS. Pesquisas maiores como "The Fibroids Registry Outcomes for Outcomes Data" (FIBROID), com um banco de dados que pesquisou mais de 2000 mulheres que realizariam embolização das artérias uterinas para tratamento do leiomioma uterino (SPIES, 2015), também chegaram à mesma conclusão, tendo mudança da média de seus scores de mais de 35 pontos tanto na severidade dos sintomas quanto na QVRS.

Para o nosso conhecimento, após pesquisa realizada no PUBMED, esta é a primeira pesquisa de tradução e validação do UFS-QOL em uma língua diferente da língua inglesa. Recentemente, o UFS-QOL sofreu uma leve modificação para mulheres que foram submetidas a histerectomia (COYNE, 2012). Países não americanos têm utilizado este questionário para mulheres com leiomioma uterino sem validá-lo, como um estudo realizado na Coréia (LEE, 2015). Este estudo foi realizado 3, 6 e 12 meses após o tratamento de pacientes com adenomiose e leiomioma uterino que foram submetidas a ablação focal de alta intensidade guiada por ultrassom e mostrou aumento dos scores das subescalas do UFSQOL assim como redução dos tumores e melhora da QVRS (LEE, 2015).

Nossa pesquisa apresentou algumas limitações tais como o fato da técnica de tradução ser considerada híbrida e a não avaliação da validade de critério. Esta última consiste no grau de eficácia de avaliar a correlação do UFS-QOL com uma ferramenta clínica que seja considerada padrão-ouro. Neste caso nós teríamos que disponibilizar a técnica de espectofotometria por hematina alcalina para quantificar a perda sanguínea. 
Finalmente, apesar dos grupos controle e caso serem diferentes no que diz respeito a idade e comorbidades, não acreditamos que estas variáveis causem um grande impacto em nossos resultados, similarmente a pesquisa de Spies et al. (SPIES, 2002).

Acreditamos que encontramos nosso objetivo de confirmar que o UFS-QOL pode ser traduzido para o português brasileiro sem prejuízo, ou seja, a versão para a língua portuguesa poderia ser adequada para identificar as mulheres com leiomioma uterino da mesma forma que o faria em países de língua inglesa. Isso se comprova com a análise estatística e com a comparação desta análise com a pesquisa de Spies et al (SPIES, 2002). A versão do UFS-QOL para a língua portuguesa é um instrumento válido e confiável para avaliar a QVRS das mulheres com leiomioma uterino e demonstrou boa consistência interna, validade de discriminação, validade de construto, teste-reteste e responsividade.

Nossa expectativa é que a tradução e validação do questionário seja útil como ferramenta para mensurar o impacto dos sintomas e o resultado das intervenções relacionadas com o leiomioma uterino em nosso país e fortaleça pesquisas futuras em nossos cenários. 


\section{CONCLUSÃO}

A versão em português brasileiro do UFS-QOL é um instrumento válido e confiável para avaliação da QVRS de mulheres com leiomioma uterino e demonstrou boa consistência interna, validade de discriminação, validade de construto, validade estrutural, teste-reteste e responsividade. 


\section{REFERÊNCIAS BIBLIOGRÁFICAS}

1. Drayer, JM, Catherino WH. Prevalence, morbidity and current medical management of uterine leiomyomas. Int J Gynaecol Obstet 2015. doi:/10.1016/j.ijgo.2015.04.051.

2. Moroni R, Vieira C, Ferriani R, Candido-dos-Reis F, Brito L. Pharmacological treatment of uterine fibroids. Ann Med Health Sci Res 2014; 4 (Suppl 3): S185-92.

3. DATASUS. Sistema de Informações Hospitalares do SUS (SIH/SUS): Banco de Dados. Accessed in: 3 october 2015, < http://www.datasus.gov.br>

4. Stewart EA. Clinical Practice. Uterine fibroids. N Engl J Med 2015;372(17):1646-55.

5. Brito LG, Panobianco MS, Sabino-de-Freitas MM et al. Uterine leiomyoma: understanding the impact of symptom on women's lives. Reproductive Health, 2014, 11 (1): 10

6. Brito LG, Panobianco MS, de Azevedo GD et al. Motivational factors for women undergoing hysterectomy for uterine leiomyoma. Acta Obstet Gynecol Scand 2013; 92 (11): 1337-8.

7. Spies JB, Coyne K, Guaou Guaou N et al. The UFS-QOL, a new disease-specific symptom and health-related quality of life questionnaire for leiomyomata. Obstet Gynecol 2002; 99 (2): 290-300.

8. Harding G, Coyne KS, Thompson CL, Spies JB. The responsiveness of the uterine fibroid symptom and health-related quality of life questionnaire (UFS-QOL) Heath and Quality of Life Outcomes 2008, 6: 99

9. Coyne KS, Margolis MK, Bradley LD et al. Further Validation of The Uterine Fibroid Symptom and Quality-of-life Questionnaire. Value in Health 2012 (1): 135-142.

10. Kottner J, Audige L, Brorson S et al. Guidelines for reporting reliability and agreement studies (GRRAS) were proposed. J Clin Epidemiol 2011; 64 (1): 96-106. 
11. Ciconelli RM, Ferraz MB, Santos W, Meinao I, Quaresma MR. Tradução para a lingua portuguesa e validaçao do questionário genérico de avaliação de qualidade de vida SF-36. Rev Bras Reumatol 1999; 39 (13): 143-150.

12. Ware JE Jr, Sherbourne CD. The MOS 36-item-short-form health survey (SF-36). Med Care 1992, 30: 473-83.

13. Cronbach $\amalg$. Coefficient alpha and the internal structure of tests. Psychometrika 1951; 16 (3): 297-334.

14. Spies JB, Myers ER, Worthington-Kirsch R et al. The FIBROID Registry: symptom and quality-of-life status 1 year after therapy. Obstet Gynecol 2015; 106 (6): 1309-18.

15. Coyne KS, Margolis MK, Murphy J, Spies J. Validation of the UFS-QOL-hysterectomy questionnaire: modifying an existing measure for comparative effectiveness research. Value Health 2012; 15 (5): 674-9.

16. Lee JS, Hong GY, Park BJ, Kim TE. Ultrasound-guided high-intensity focused ultrasound treatment for uterine fibroid \& adenomyosis: a single center experience from the Republic of Korea. Ultrason Sonochem 2015; 682-7.

17. Danielsen AK, Pommergaard HC, Burcharth J, Angenete E, Rosenberg J. Translation of questionnaires measuring health related quality of life is not standardized: a literature based research study. Plos One 2015; 10 (5):e0127050.

18. Stewart EA et al. Uterine fibroids. Nature Reviews 2016; 2:1-18.

19. Moroni, RM et al. Combined oral contraceptives for treatment of women with uterine fibroids and abnormal uterine bleeding: a systematic review. Gynecol Obstet Invest 2015; 79 (3): 145-52

20. Terwee CB, Bot SD, de Boer MR, van der Windt DA, Knol DL, Dekker J, Bouter LM, de Vet HC. Quality criteria were proposed for measurement properties of health status questionnaires. J Clin Epidemiol. 2007; 60 (1): 34-42. doi:10.1016/j.jclinepi.2006. 03.012 
21. Guillemin F, Bomabardier C, Beaton D. Cross-cultural adaptation of health-related quality of life measures: literature review and proposed guidelines. J Clin Epidemiol. 1993; 46: 1417-

22. McGraw K, Wong S. Forming inferences about some intraclass correlation coefficients. Psychol Methods. 1996; 1 (1): 30-46 


\title{
APÊNDICES E ANEXOS
}

\section{Apêndice I - Termo de Consentimento Livre e Esclarecido - grupo caso}

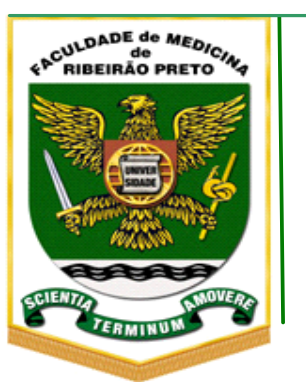

\section{FACULDADE DE MEDICINA DE RIBEIRÃO PRETO-USP DEPARTAMENTO DE GINECOLOGIA E OBSTETRÍCIA}

\author{
Av. Bandeirantes, 3900 - $8^{\circ}$ andar - Ribeirão Preto-SP - CEP 14049- 900 \\ Fone (016) 3602-2231 - Fax (016) 3633-1028
}

Termo de consentimento LIVRE E ESCLARECIDO - GRUPO CASO

1. NOME DA PESQUISA: "Validação e tradução do questionário "Uterine Fibroid Symptom and Quality of Life" para o português".

PESQUISADOR RESPONSÁVEL: Dr. Luiz Gustavo Oliveira Brito e Dra. Daniela Alves Malzone Lott

2. Você está sendo convidada a participar da pesquisa: Validação e tradução do questionário "Uterine Fibroid Symptom and Quality of Life" para o português.

\section{O que é a pesquisa? Qual é o seu objetivo?}

Os leiomiomas são os tumores mais comuns nas mulheres que estão na faixa de idade em que menstruam. De cada 10 mulheres, 8 apresentam miomas, porém dessas 8,duas costumam ter queixas associadas. Os sintomas mais comuns são: queixa de aumento no volume ou na duração da menstruação ou com irregularidade menstrual ou com problemas como dor na barriga, barriga inchada e "caroço" no útero. Quando não se consegue tratar essas pacientes que menstruam em nossa região, elas costumam ser encaminhadas para o Ambulatório de Cirurgia Ginecológica (ACGC) do Hospital das Clínicas da Faculdade de Medicina de Ribeirão Preto - Universidade de São Paulo para acompanhamento. Nesse setor é oferecido vários tratamentos com medicações para controlar esses sintomas, assim como cirurgia para retirada dos miomas (miomectomia) ou a própria retirada do útero (histerectomia).

Porém, não sabemos se a vida de uma mulher melhora de maneira completa após um tratamento que realizamos para ela. Sabemos que vocês melhoram ou pioram das queixas, mas não sabemos se isso quer dizer se vocês melhoram a qualidade de vida de vocês. Isso acontece porque não existe nenhum questionário no Brasil sobre essa doença, nem traduzido de maneira oficial.

Gostaríamos de aplicar um questionário criado nos Estados Unidos com você, que tem o leiomioma uterino. Chama-se UFS-QOL. Ele foi modificado por dois especialistas em tradução para o português, e o que você tem que fazer é ler, e responder as suas perguntas. Se você tiver dificuldade para ler, poderemos ler juntos para você entender. Queremos que você além de responder, se perceber alguma dificuldade no entendimento de alguma palavra e/ou pergunta, que nos fale, para podermos adaptar melhor esse questionário a nossa língua. Faremos esse questionário antes da sua consulta com o médico, para não causar prejuízos a você. Você também não precisará vir ao hospital em outro dia para responder, tudo é feito no mesmo dia em uma única etapa. 
Além desse questionário, você responderá um outro questionário, para comparar se as respostas dadas em um são similares ou não ao outro. 0 tempo de preenchimento desse questionário leva, no mínimo, 20 minutos. Mas você poderá ficar a vontade para demorar o quanto quiser para responder.

Algumas mulheres poderão responder novamente ao questionário UFS-QOL algumas semanas depois. Uma delas pode ser você; nesse caso, a pesquisa terá duas etapas. Isso será feito durante o seu retorno, você não precisará vir só para isso.

\section{0 que acontece se eu não quiser participar da pesquisa ou desistir durante a realização da mesma ?}

As pacientes que não quiserem assinar o termo de consentimento estarão automaticamente excluídas do trabalho, porém não deixarão de ser atendidas nos ambulatórios.

Caso você abandone a pesquisa após o seu início, ou seja, caso você for escolhida para repetir o preenchimento de um dos questionários e não queira, não há problema ou prejuízo algum ao seu tratamento, fique livre para escolher. Não haverá recompensa financeira para os voluntários controles e pacientes que participarem do estudo. E se existirem gastos adicionais estes serão absorvidos pelo orçamento da pesquisa.

Assim, participando deste estudo, você estará colaborando para um melhor tratamento do leiomioma uterino, afinal voce tem esta doença. Desta forma, a possibilidade de se estudar melhor e aumentar as opções de tratamento para as mulheres com miomatose uterina poderá representar um benefício não só para você, mas poderá melhorar a qualidade de vida de muitas outras pacientes no futuro. Uma via desse termo ficará com você, a outra conosco.

Ribeirão Preto I 1 


\title{
Apêndice II - Termo de Consentimento Livre e Esclarecido - grupo controle
}

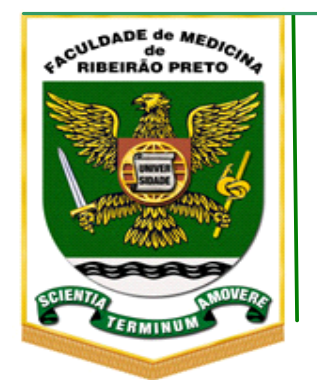

\section{FACULDADE DE MEDICINA DE RIBEIRÃO PRETO-USP DEPARTAMENTO DE GINECOLOGIA E OBSTETRÍCIA}

\author{
Av. Bandeirantes, 3900 - $8^{\circ}$ andar - Ri beirão Preto-SP - CEP 14049- 900
} Fone (016) 3602-2231 - Fax (016) 3633-1028

Termo de consentimento LIVRE E ESCLARECIDO - GRUPO CONTROLE

1. NOME DA PESQUISA: "Validação e tradução do questionário "Uterine Fibroid Symptom and Quality of Life" para o português".

PESQUISADOR RESPONSÁVEL: Dr. Luiz Gustavo Oliveira Brito e Dra. Daniela Alves Malzone Lott

2. Você está sendo convidada a participar da pesquisa: Validação e tradução do questionário "Uterine Fibroid Symptom and Quality of Life" para o português.

\section{O que é a pesquisa? Qual é o seu objetivo?}

Os leiomiomas são os tumores mais comuns nas mulheres que estão na faixa de idade em que menstruam. De cada 10 mulheres, 8 apresentam miomas, porém dessas 8 ,duas costumam ter queixas associadas. Os sintomas mais comuns são: queixa de aumento no volume ou na duração da menstruação ou com irregularidade menstrual ou com problemas como dor na barriga, barriga inchada e "caroço" no útero. Quando não se consegue tratar essas pacientes que menstruam em nossa região, elas costumam ser encaminhadas para o Ambulatório de Cirurgia Ginecológica (ACGC) do Hospital das Clínicas da Faculdade de Medicina de Ribeirão Preto - Universidade de São Paulo para acompanhamento. Nesse setor é oferecido vários tratamentos com medicações para controlar esses sintomas, assim como cirurgia para retirada dos miomas (miomectomia) ou a própria retirada do útero (histerectomia).

Porém, não sabemos se a vida de uma mulher melhora de maneira completa após um tratamento que realizamos para ela. Isso acontece porque não existe nenhum questionário no Brasil sobre essa doença, nem traduzido de maneira oficial.

Gostaríamos de aplicar um questionário criado nos Estados Unidos com você, que não tem o leiomioma uterino. Chama-se UFS-QOL. Apesar de você não ter a doença, precisamos que você responda essas perguntas, para ver se as respostas delas estão mais relacionadas a mulheres que tem a doença. Por isso voce faria parte do grupo chamado controle. Ele foi modificado por dois especialistas em tradução para o português, e o que você tem que fazer é ler, e responder as suas perguntas. Se você tiver dificuldade para ler, poderemos ler juntos para você entender. Queremos que você além de responder, se perceber alguma dificuldade no entendimento de alguma palavra e/ou pergunta, que nos fale, para podermos adaptar melhor esse questionário a nossa língua. Faremos esse questionário antes da sua consulta com o médico, para não causar prejuízos a você. Você também não precisará vir ao hospital em outro dia para responder, tudo é feito no mesmo dia em uma única etapa.

Além desse questionário, você responderá um outro questionário, para comparar se as respostas dadas em um são similares ou não ao outro. $O$ tempo de preenchimento desse questionário leva, no mínimo, 20 minutos. Mas você poderá ficar a vontade para demorar o quanto quiser para responder. 
Algumas mulheres poderão responder novamente ao questionário UFS-QOL algumas semanas depois. Uma delas pode ser você; nesse caso, a pesquisa terá duas etapas. Isso será feito durante o seu retorno, você não precisará vir só para isso.

\section{4. $O$ que acontece se eu não quiser participar da pesquisa ou desistir durante a realização da mesma ?}

As pacientes que não quiserem assinar o termo de consentimento estarão automaticamente excluídas do trabalho, porém não deixarão de ser atendidas nos ambulatórios.

Caso você abandone a pesquisa após o seu início, ou seja, caso você for escolhida para repetir o preenchimento de um dos questionários e não queira, não há problema ou prejuízo algum ao seu tratamento, fique livre para escolher. Não haverá recompensa financeira para os voluntários controles e pacientes que participarem do estudo. E se existirem gastos adicionais estes serão absorvidos pelo orçamento da pesquisa.

Assim, participando deste estudo, você estará colaborando para um melhor tratamento do leiomioma uterino, mesmo não tendo esta doença. Desta forma, a possibilidade de se estudar melhor e aumentar as opções de tratamento para as mulheres com miomatose uterina poderá representar um benefício para a qualidade de vida de muitas outras pacientes no futuro. Uma via desse termo ficará com você, a outra conosco.

Ribeirão Preto 1

Assinatura do Pesquisador

\section{PESQUISADOR RESPONSÁVEL:}

Dr. Luiz Gustavo Oliveira Brito - CRM: 118.697 - SP

Telefone de contato: 16-3602-2311 (Ambulatório de Cirurgia Ginecológica, quartas e sextas à tarde, das 13 às 17 horas) 


\section{APÊNDICE III - Ficha de identificação}

Projeto de Pesquisa: Validação e tradução do questionário UTERINE FIBROID SYMPTOM AND QUALITY OF LIFE (UFS-QOL) para a língua portuguesa

\section{FICHA DE IDENTIFICAÇÃO}

Nome

Registro

Idade Paridade DUM Pat

Med IMC

Anos de escolaridade Profissão

Grupo: ( ) controle ( ) estudo

Se grupo estudo, marcar queixa clínica: ( ) SUA（） Dor pélvica（ ）Compressão extrínseca（ ） outros:

Data da entrevista:

Data do teste-reteste, se realizado:

Apresentou dúvidas ou sugestões de modificar a pergunta:

Se sim, quais foram: 


\title{
APÊNDICE IV - Questionário UFS-QOL traduzido e adaptado à
}

língua portuguesa (versão final)

\author{
Nome da pesquisa: "Validação do questionário: Uterine Fibroid Symptom and Quality of Life (UFS-QOL) para a \\ límgua Portuguesa" \\ Pesquisadores responsáveis: Dra Daniela Alves Malzone Lott e Dr. Luiz Gustavo Oliveira Brito
}

RUBRICA DA PACIENTE:

IDENTIDADE ou REGISTRO DA PACIENTE:

DATA:

\section{QUESTIONÁRIO SOBRE SINTOMAS DO LEIOMIOMA/MIOMA UTERINO E QUALIDADE DE VIDA (UFS-QOL)}

Encontram-se listados, abaixo, sintomas experimentados por mulheres portadoras de mioma uterino. Avalie, por favor, a maneira como cada sintoma se relaciona com o mioma uterino ou seu ciclo menstrual. O objetivo de cada pergunta é saber o quanto cada um desses sintomas tem incomodado você nos últimos 3 meses.

Não há respostas certas ou erradas. Certifique-se, por favor, de responder cada pergunta assinalando (X) no quadrado mais apropriado. Se a pergunta não se aplicar a você, marque a resposta "nada" 
Durante os últimos 3 meses, diga o quanto você ficou incomodada com...

\begin{tabular}{|c|c|}
\hline Nada & $\begin{array}{l}\text { Muito } \\
\text { pouco }\end{array}$ \\
\hline
\end{tabular}

1. Sangramento intenso durante sua menstruação

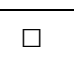

1

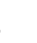

2

3

4

5

2. Eliminação de coágulos durante a menstruação
1

3. Variação na duração do seu ciclo menstrual quando comparada com seus ciclos anteriores

4. Variação no intervalo do seu ciclo menstrual quando comparada com seus ciclos anteriores

5. Sensação de aperto ou pressão na região do baixo ventre ("pé da barriga")

1

1

1

2

2

4

5

3

6. Aumento da vontade de urinar durante o dia

1

2

3

4

5

7. Aumento da vontade de urinar durante a noite

8. Sensação de cansaço

$\begin{array}{lllll}1 & 2 & 3 & 4 & 5\end{array}$

1

2

3

45

1

As próximas questões procuram saber sobre seus sentimentos e experiências em relação ao impacto do leiomioma uterino em sua vida. Considere, por favor, cada pergunta na medida em que ela se relaciona com suas experiências sobre esse assunto nos últimos 3 meses.

Não há respostas certas ou erradas. Certifique-se, por favor, de responder cada pergunta assinalando (X) no quadrado mais apropriado. Se a pergunta não se aplicar a você, marque a resposta "nunca" 


\begin{tabular}{lccccc}
\hline Durante os últimos 3 meses, com que & Nunca & Poucas & Algumas & A maior & 0 \\
frequência seus sintomas relacionados ao do & tempo \\
mioma uterino... & vezes & vezes & $\begin{array}{c}\text { pampo } \\
\text { todo }\end{array}$
\end{tabular}

9. Fizeram com que você se sentisse ansiosa sobre a falta de previsão da data ou duração da menstruação?

10. Fizeram com que você se sentisse ansiosa em relação a viajar?

11. Interferiram em suas atividades físicas?

12. Fizeram com que você se sentisse cansada ou exausta?

13. Fizeram com que você diminuísse a quantidade de tempo que você usa em exercícios ou outras atividades físicas?

14. Fizeram com que você se sentisse como se não tivesse controle sobre sua vida?

15. Fizeram com que você se sentisse preocupada com possibilidade de manchar peças íntimas?

16. Fizeram com que você se sentisse menos produtiva em termos de trabalho?

17. Fizeram com que você se sentisse com sono ou tontura durante o dia?

18. Fizeram com que você tivesse a sensação de ganho de peso?

19. Fizeram com que você sentisse que estava difícil realizar suas atividades habituais?

20. Interferiram em suas atividades sociais? 
21. Fizeram você perceber sobre o tamanho e a aparência da sua barriga?

22. Fizeram com que você se sentisse preocupada em manchar roupas de cama?
1

2

3

4

5

1

2

3

4

5

1

2

3

4

5 


\begin{tabular}{lccccc}
\hline $\begin{array}{l}\text { Durante os últimos } 3 \text { meses, com que } \\
\text { frequência seus sintomas relacionados ao } \\
\text { mioma uterino... }\end{array}$ & Nunca & $\begin{array}{c}\text { Poucas } \\
\text { vezes }\end{array}$ & $\begin{array}{c}\text { Algumas } \\
\text { vezes }\end{array}$ & $\begin{array}{c}\text { A maior } \\
\text { parte do } \\
\text { tempo }\end{array}$ & $\begin{array}{c}\text { tempo } \\
\text { todo }\end{array}$
\end{tabular}

23. Fizeram com que você se sentisse triste, desanimada ou desesperada?

24. Fizeram com que você se sentisse deprimida ou abatida?

25. Fizeram com que você se sentisse extremamente cansada?

26. Fizeram com que você se sentisse preocupada ou ansiosa em relação à sua saúde?

27. Fizeram com que você planejasse suas atividades com mais cuidado?

28. Fizeram com que você se sentisse incomodada por sempre carregar absorventes, absorventes internos ou roupas extras para evitar "acidentes"?

29. Causaram-Ihe constrangimento?

30. Fizeram com que você sentisse incerteza em relação ao seu futuro?

31. Fizeram com que você se sentisse irritada?

32. Fizeram com que você se sentisse preocupada em relação a manchar a parte externa da roupa?

33. Afetaram o tamanho das roupas que você costuma usar durante seus ciclos menstruais?
1

1

$$
2
$$

3

4

5

1

1

2

3

4

5

1

2

3

4

5

1

2

3

4

5

3

4

5

1

2

3

4

5

1

2

3

4

5 
34. Fizeram com que você sentisse sem controle sobre sua saúde?

$\begin{array}{lllll}1 & 2 & 3 & 4 & 5\end{array}$

35. Fizeram com que você se sentisse fraca, como se a energia tivesse sido "sugada" do seu corpo?

36. Diminuíram seu desejo sexual (vontade de ter relação)?

37. Fizeram com que você evitasse ter relações sexuais? 


\section{Apêndice V - Questionário MOS SF-36}

Versão Brasileira do MOS -SF-36

1- Em geral você diria que sua saúde é:

\begin{tabular}{|c|c|c|c|c|}
\hline Excelente & Muito Boa & Boa & Ruim & Muito Ruim \\
\hline 1 & 2 & 3 & \begin{tabular}{|l|l|}
4 & \\
\end{tabular} & 5 \\
\hline \multicolumn{5}{|c|}{$\begin{array}{l}\text { 2- Comparada há um ano atrás, como você se classificaria sua idade em geral, } \\
\text { agora? }\end{array}$} \\
\hline Muito Melhor & Um Pouco Melhor & $\begin{array}{c}\text { Quase a } \\
\text { Mesma }\end{array}$ & Um Pouco Pior & Muito Pior \\
\hline 1 & 2 & 3 & 4 & 5 \\
\hline
\end{tabular}

3- Os seguintes itens são sobre atividades que você poderia fazer atualmente durante um dia comum. Devido à sua saúde, você teria dificuldade para fazer estas atividades? Neste caso, quando?

\begin{tabular}{|c|c|c|c|}
\hline Atividades & $\begin{array}{l}\text { Sim, } \\
\text { dificulta } \\
\text { muito }\end{array}$ & $\begin{array}{l}\text { Sim, } \\
\text { dificulta } \\
\text { um pouco }\end{array}$ & $\begin{array}{l}\text { Não, não } \\
\text { dificulta } \\
\text { de modo } \\
\text { algum }\end{array}$ \\
\hline $\begin{array}{l}\text { a) Atividades Rigorosas, que } \\
\text { exigem muito esforço, tais } \\
\text { como correr, levantar objetos } \\
\text { pesados, participar em } \\
\text { esportes árduos. }\end{array}$ & 1 & 2 & 3 \\
\hline $\begin{array}{l}\text { b) Atividades moderadas, tais } \\
\text { como mover uma mesa, passar } \\
\text { aspirador de pó, jogar bola, } \\
\text { varrer a casa. }\end{array}$ & 1 & 2 & 3 \\
\hline $\begin{array}{l}\text { c) Levantar ou carregar } \\
\text { mantimentos }\end{array}$ & 1 & 2 & 3 \\
\hline $\begin{array}{l}\text { d) Subir vários lances de } \\
\text { escada }\end{array}$ & 1 & 2 & 3 \\
\hline e) Subir um lance de escada & 1 & 2 & 3 \\
\hline $\begin{array}{l}\text { f) Curvar-se, ajoelhar-se ou } \\
\text { dobrar-se }\end{array}$ & 1 & 2 & 3 \\
\hline g) Andar mais de 1 quilômetro & 1 & 2 & 3 \\
\hline h) Andar vários quarteirões & 1 & 2 & 3 \\
\hline i) Andar um quarteirão & 1 & 2 & 3 \\
\hline j) Tomar banho ou vestir-se & 1 & 2 & 3 \\
\hline
\end{tabular}

4- Durante as últimas 4 semanas, você teve algum dos seguintes problemas com seu trabalho ou com alguma atividade regular, como conseqüência de sua saúde física?

\begin{tabular}{|l|c|c|}
\hline & $\operatorname{Sim}$ & Não \\
\hline $\begin{array}{l}\text { a) Você diminui a quantidade de tempo que se dedicava } \\
\text { ao seu trabalho ou a outras atividades? }\end{array}$ & 1 & 2 \\
\hline
\end{tabular}




\begin{tabular}{|c|c|c|c|c|c|c|}
\hline & Tempo & $\begin{array}{l}\text { parte } \\
\text { do } \\
\text { tempo }\end{array}$ & $\begin{array}{c}\text { parte } \\
\text { do } \\
\text { tempo }\end{array}$ & $\begin{array}{c}\text { do } \\
\text { tempo }\end{array}$ & $\begin{array}{c}\text { parte do } \\
\text { tempo }\end{array}$ & \\
\hline $\begin{array}{l}\text { a) Quanto } \\
\text { tempo você tem } \\
\text { se sentindo } \\
\text { cheio de vigor, } \\
\text { de vontade, de } \\
\text { força? }\end{array}$ & 1 & 2 & 3 & 4 & 5 & 6 \\
\hline $\begin{array}{l}\text { b) Quanto } \\
\text { tempo você tem } \\
\text { se sentido uma } \\
\text { pessoa muito } \\
\text { nervosa? }\end{array}$ & 1 & 2 & 3 & 4 & 5 & 6 \\
\hline $\begin{array}{l}\text { c) Quanto } \\
\text { tempo você tem } \\
\text { se sentido tão } \\
\text { deprimido que } \\
\text { nada pode } \\
\text { anima-lo? }\end{array}$ & 1 & 2 & 3 & 4 & 5 & 6 \\
\hline $\begin{array}{l}\text { d) Quanto } \\
\text { tempo você tem } \\
\text { se sentido } \\
\text { calmo ou } \\
\text { tranqüilo? }\end{array}$ & 1 & 2 & 3 & 4 & 5 & 6 \\
\hline $\begin{array}{l}\text { e) Quanto } \\
\text { tempo você tem } \\
\text { se sentido com } \\
\text { muita energia? }\end{array}$ & 1 & 2 & 3 & 4 & 5 & 6 \\
\hline $\begin{array}{l}\text { f) Quanto } \\
\text { tempo você tem } \\
\text { se sentido } \\
\text { desanimado ou } \\
\text { abatido? }\end{array}$ & 1 & 2 & 3 & 4 & 5 & 6 \\
\hline $\begin{array}{l}\text { g) Quanto } \\
\text { tempo você tem } \\
\text { se sentido } \\
\text { esgotado? }\end{array}$ & 1 & 2 & 3 & 4 & 5 & 6 \\
\hline $\begin{array}{l}\text { h) Quanto } \\
\text { tempo você tem } \\
\text { se sentido uma } \\
\text { pessoa feliz? }\end{array}$ & 1 & 2 & 3 & 4 & 5 & 6 \\
\hline $\begin{array}{l}\text { i) Quanto tempo } \\
\text { você tem se } \\
\text { sentido } \\
\text { cansado? }\end{array}$ & 1 & 2 & 3 & 4 & 5 & 6 \\
\hline
\end{tabular}


10- Durante as últimas 4 semanas, quanto de seu tempo a sua saúde física ou problemas emocionais interferiram com as suas atividades sociais (como visitar amigos, parentes, etc)?

\begin{tabular}{|c|c|c|c|c|}
\hline $\begin{array}{c}\text { Todo } \\
\text { Tempo }\end{array}$ & $\begin{array}{c}\text { A maior parte } \\
\text { do tempo }\end{array}$ & $\begin{array}{c}\text { Alguma parte do } \\
\text { tempo }\end{array}$ & $\begin{array}{c}\text { Uma } \\
\text { pequena } \\
\text { parte do } \\
\text { tempo }\end{array}$ & $\begin{array}{c}\text { Nenhuma } \\
\text { parte do } \\
\text { tempo }\end{array}$ \\
\hline 1 & 2 & 3 & 4 & 5 \\
\hline
\end{tabular}

11- O quanto verdadeiro ou falso é cada uma das afirmaçōes para você?

\begin{tabular}{|l|c|c|c|c|c|}
\hline & $\begin{array}{c}\text { Definitivament } \\
\text { e verdadeiro }\end{array}$ & $\begin{array}{c}\text { A } \\
\text { maioria } \\
\text { das } \\
\text { vezes } \\
\text { verdadei } \\
\text { ro }\end{array}$ & $\begin{array}{c}\text { Não } \\
\text { sei }\end{array}$ & $\begin{array}{c}\text { A } \\
\text { maiori } \\
\text { a das } \\
\text { vezes } \\
\text { falso }\end{array}$ & $\begin{array}{c}\text { Definitiva } \\
- \\
\text { mente } \\
\text { falso }\end{array}$ \\
\hline $\begin{array}{l}\text { a) Eu costumo } \\
\text { obedecer um pouco } \\
\text { mais facilmente que } \\
\text { as outras pessoas }\end{array}$ & 1 & 2 & 3 & 4 & 5 \\
\hline $\begin{array}{l}\text { b) Eu sou tão } \\
\text { saudável quanto } \\
\text { qualquer pessoa } \\
\text { que eu conheço }\end{array}$ & 1 & 2 & 3 & 4 & 5 \\
\hline $\begin{array}{l}\text { c) Eu acho que a } \\
\text { minha saúde vai } \\
\text { piorar }\end{array}$ & 1 & 2 & 3 & 4 & 5 \\
\hline $\begin{array}{l}\text { d) Minha saúde é } \\
\text { excelente }\end{array}$ & 1 & 2 & 3 & 4 & 5 \\
\hline
\end{tabular}




\section{ANEXO I - Autorização para realização da Pesquisa}

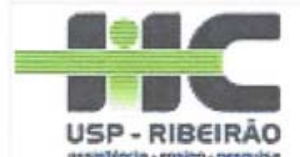

\section{HOSPITAL DAS CLIINICAS DA \\ FACULDADE DE MEDICINA DE \\ RIBEIRÃO PRETO DA USP -}

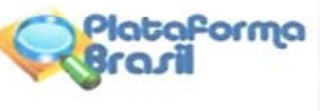

\section{PARECER CONSUBSTANCIADO DO CEP}

\section{DADOS DO PROJETO DE PESQUISA}

Título da Pesquisa: "Validação e tradução do questionário "Uterine fibroid symptom and quality of life" para a lingua portuguesa

Pesquisador: Daniela Alves Malzone Lott

Área Temática:

Versão: 3

CAAE: 20629413.1.0000.5440

Instituição Proponente: Hospital das Clinicas da Faculdade de Medicina de Ribeirāo Preto da USP -

Patrocinador Principal: Financiamento Próprio

\section{DADOS DO PARECER}

Número do Parecer: 829.053

Data da Relatoria: 18/08/2014

\section{Apresentação do Projeto:}

Estudo prospectivo e observacional, realizado nos Ambulatórios de Uroginecologia, Cirurgia Ginecológica e Reconstrutiva Pélvica do Hospital das Clinicas da Faculdade de Medicina de Ribeirão da Universidade de São Paulo (HCFMRP-USP). O projeto é intitulado: Validação e tradução do questionário "Uterine Fibroid Symptom and Quality of Life" para o português e possui como pesquisadores: Luiz Gustavo Oliveira Brito, Rui Alberto Ferriani, Carolina Sales Vieira, Pedro Sérgio Magnani, Francisco José Candido dos Reis, Antonio Alberto Nogueira, Daniela Alves Malzone Lott, Mariana Alves Fernandes Arouca

Objetivo da Pesquisa:

Traduzir e validar o questionário Uterine Fibroid Symptom and Quality of Life (UFS-QOL) para o português.

Avaliação dos Riscos e Beneficios:

Beneficio: $O$ projeto pode contribuir para um melhor tratamento do leiomioma uterino, com a possibilidade de se estudar melhor e aumentar as opçōes de tratamento para as mulheres com miomatose uterina. Como risco os pesquisadores citam o desconforto seja responder por alguns minutos o questionário.

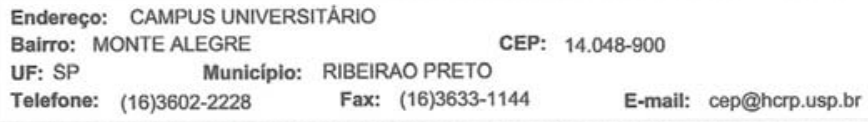




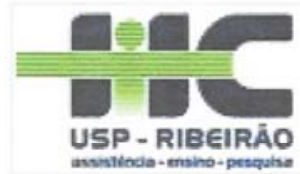

\section{HOSPITAL DAS CLÍNICAS DA FACULDADE DE MEDICINA DE RIBEIRÃO PRETO DA USP -}

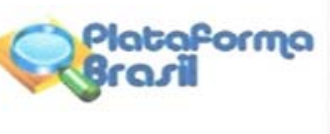

Continuaçåo do Parecer. 829.053

Comentários e Considerações sobre a Pesquisa:

A leiomiomatose uterina é a patologia ginecológica mais comum no menacme, podendo atingir 80 a $90 \%$ das mulheres. A avaliação da qualidade de vida dessas mulheres é extremamente importante, pois ajuda na escolha do melhor tratamento para esta doença. Porém, existe apenas um questionário especifico para avaliação de qualidade de vida em mulheres com leiomiomas uterinos e está disponivel apenas em língua inglesa. Trata-se do Uterine Fibroid Symptom and Quality of Life (UFS-QOF).

O questionário UFS-QOL é um instrumento de 37 perguntas; as primeiras oito perguntas relacionam-se com os sintomas relacionados ao leiomioma uterino e resume o dominio severidade dos sintomas. Os demais domínios relacionados à qualidade de vida da mulher (preocupaçăo, atividades, energia/humor, controle, auto-consciência, função sexuais) são analisados pelas demais 29 perguntas.

Todas as respostas tem cinco opções de escolha, de acordo com a escala de Likert, variando de "nenhuma vez" (none of the time) até "todo o tempo" (all of the time), cujo score respectivo é 1 e 5 . Existe uma fórmula diferenciada de cálculo do score para o dominio de severidade dos sintomas, e dos demais domínios. Quanto maior o score do domínio de severidade das queixas, pior são os sintomas; quanto menor for o score dos dominios relacionados à qualidade de vida, pior é a qualidade de vida.

\section{Considerações sobre os Termos de apresentação obrigatória:}

Trata-se de projeto de pesquisa já analisado anteriormente pelo CEP que permanceu em pendência para adequaçãos nos Termos de Consentimento Livre e Esclarecido. Os pesquisadores responsáveis encaminharam novas versōes dos documentos, devidamente corrigidas: Termo de Consentimento Livre e Esclarecido (versão 3.0) - grupo caso, Termo de Consentimento Livre e Esclarecido (versão 2.0) - grupo controle e o Projeto detalhado - Versão 3.0 - 18 de julho de 2014.

Recomendações:

Não se aplica.

Conclusōes ou Pendências e Lista de Inadequaçöes:

Diante do exposto e à luz da Resolução CNS 466/2012, o Projeto detalhado - Versão 3.0 - 18 de julho de 2014, assim como o Termo de Consentimento Livre e Esclarecido (versão 3.0) - grupo caso e o Termo de Consentimento Livre e Esclarecido (versão 2.0) - grupo controle, podem ser enquadrados na categoria APROVADO.

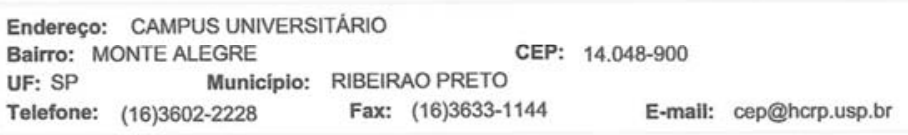




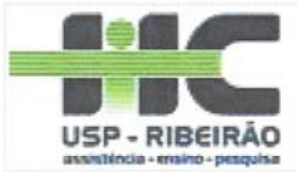

\section{HOSPITAL DAS CLÍNICAS DA \\ FACULDADE DE MEDICINA DE RIBEIRÃO PRETO DA USP -}

Continuaçâo do Parecer: 829.053

Situação do Parecer:

Aprovado

Necessita Apreciação da CONEP:

Não

Consideraçöes Finais a critério do CEP:

Projeto Aprovado: Tendo em vista a legislação vigente, devem ser encaminhados ao CEP, relatórios parciais anuais referentes ao andamento da pesquisa e relatório final ao término do trabalho. Qualquer modificação do projeto original deve ser apresentada a este CEP em nova versão, de forma objetiva e com justificativas, para nova apreciação.

RIBEIRAO PRETO, 13 de Outubro de 2014

Assinado por:

MARCIA GUIMARÃES VILLANOVA

(Coordenador)

Endereço: CAMPUS UNIVERSITÁRIO

Bairro: MONTE ALEGRE

CEP: $14.048-900$

UF: SP Municipio: RIBEIRAO PRETO

Telefone: (16)3602-2228 Fax: (16)3633-1144

E-mail: cep@hcrp.usp.br 


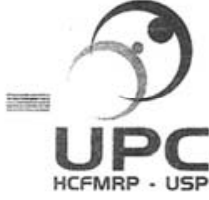

HOSPITAL DAS CLINICAS DA FACULDADG DE MEDICINA DE RIBEIRÃO PRETO DA UNIVERSIDADE DE SÃO PAULO

www.herp.fmrp.usp.br

PROJETO DE PESQUISA

Ribeirão Preto, 12 de IUlth 20

Sistema UPC n' 1072

Ilustríssima Senhora

Dr. ${ }^{a}$ Marcia Guimarâes Villanova

MD. Coordenadora do Comitê de Ética em Pesquisa

Do HCFMRP-USP e da FMRP-USP

Senhora Coordenadora,

Encaminho em anexo o projeto de pesquisa intitulado

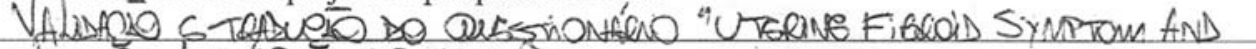

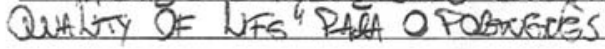

juntamente com a documentação necessária para avaliação ética deste Comitê.

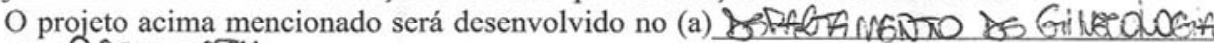

\section{Oesteterit}

Informo também que o pesquisador responsável e o orientador possuem currículo Lattes.

$\mathrm{O}$ orçamento do presente projeto foi analisado pela equipe técnica da UPC antes da submissão ao Comitê e foi $\mathrm{APCOU}$ HDO

Atenciosamente,

- havis Onstant orfon's

Pesquisadó Principal ou Aluno (nome completo e assinatura)

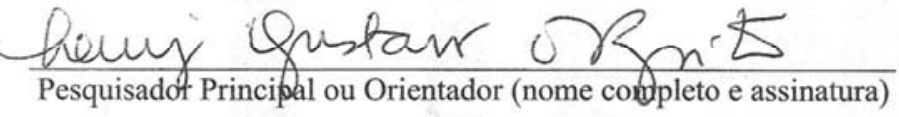

De acordo:

Prof. Dr. Rui Alberto Ferriani

Chefe do Departamento de Ginecoiogia

Chefe de Bepartancifiento (assinatura e carimbo)

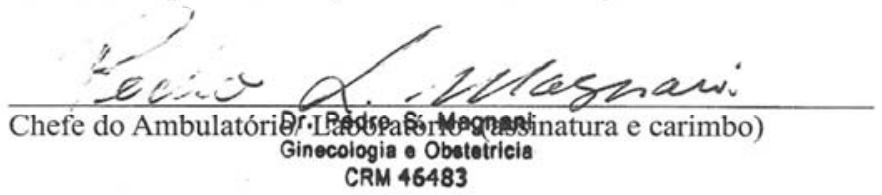

Obs.: Caso u._um chefe possua vinculo com a pesquisa, deverá ser solicitada assinatura do suplente.

Ap's assinatura em todos os campos, digitalizar toda a documentação do check list e encaminhar ao CEP via Plataforma Brasil.

HC - Campus Universitário

Monte Alegre 14048-900 Ribeirão Preto SP

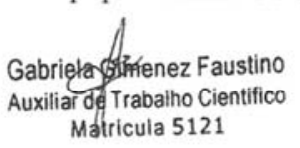

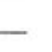




\section{Portuguese validation of UFS-QOL}

Luiz Gustavo Brito <lgobrito@gmail.com>

11 de março de 2013 15:24

Para: spiesj@georgetown.edu

Dear Prof. Spies:

Our group studies uterine fibroids and in Brazil we do not have any questionnaire specific for this disease. We would to like to know if you give us the authorization for translating and validating UFS-QOL to our language.

Thank you very much for your attention.

Best regards

Luiz Gustavo Oliveira Brito

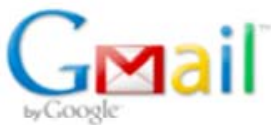

\section{Portuguese validation of UFS-QOL}

Spies, James <SPIESJ@gunet.georgetown.edu>

12 de março de 2013 15:22

Para: Luiz Gustavo Brito<lgobrito@gmail.com>

Cc: Molly Astudillo <mastudillo@sirweb.org>

I have no objection. You need to register this effort with the SIR Foundation, which holds the copyright. They can also tell you if there already is a Portuguese version or a version available for Brazil. I have copied them on this reply

J Spies

James B. Spies, MD, MPH

Professor and Chair 


\section{Uterine Fibroid Symptom and Health Related Quality-of-Life Questionnaire:}

\section{License Agreement}

THIS AGREEMENT, is made effective beginning (date) March $18^{\text {th }} 2013$ between the Society of Interventional Radiology Foundation a 501(c)(3) nonprofit association having a place of business at 3975 Fair Ridge Drive, Suite 400 North, Fairfax, Virginia 22033, incorporated in the State of Illinois ("SIR Foundation"), and Ribeirão Preto School of Medicine, University of São Paulo, a company having its principal offices at Avenida Bandeirantes, $3900-8^{\text {th }}$ floor - Monte Alegre Ribeirão Preto, SP, Brazil ("Licensee").

IN WITNESS WHEREOF, the parties respective duly authorized officers have signed this Agreement, effective as of the day and year first above written.

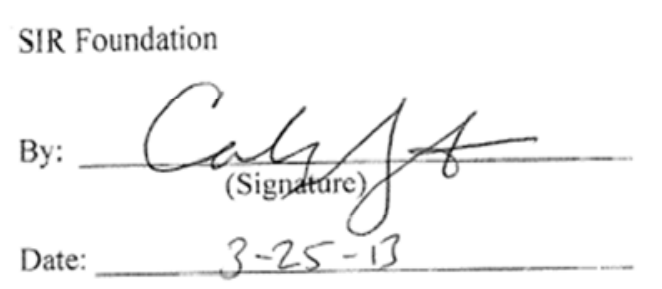

Name: $\quad$ Carolyn Strain, MA, MS (Typed)

Its: Executive Director, SIR Foundation

Address: $\quad 3975$ Fair Ridge Drive Suite 400 North, Fairfax, VA 22033
Department of Gynecology and Obstetrics, Ribeirão Preto School of Medicine, University of São Paulo.

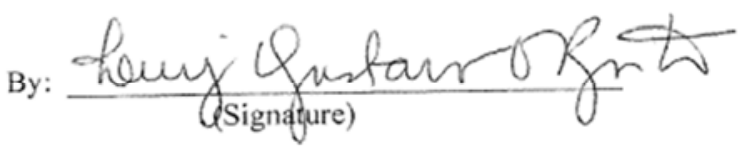

Date: March $18^{\text {th }} 2013$

Name: LUIZ GUSTAVO OLIVEIRA BRITO, $\mathrm{MD}, \mathrm{PhD}$

$$
\text { (Typed) }
$$

Its: Assistant Physician, Hospital das Clínicas, Department of Gynecology and Obstetrics, Ribeirão Preto School of Medicine, University of São Paulo

Address: Avenida Bandeirantes, $3900-8^{\text {th }}$ floor - Monte Alegre - Ribeirão Preto - São Paulo State - Brazil 


\section{ANEXO II - Questionário original UFS-QOL}

\section{APPENDIX A}

Pt. Initials:

Pt. ID:

Date:

\section{UTERINE FIBROID SYMPTOM AND HEALTH-RELATED QUALITY OF LIFE QUESTIONNAIRE (UFS-QOL)}

Listed below are symptoms experienced by women who have uterine fibroids. Please consider each symptom as it relates to your uterine fibroids or menstrual cycle. Each question asks how much distress you have experienced from each symptom during the previous 3 months.

There are no right or wrong answers. Please be sure to answer every question by checking $(\checkmark)$ the most appropriate box. If a question does not apply to you, please mark "not at all" as a response.

$\begin{aligned} & \text { During the previous } 3 \text { months, how distressed } \\ & \text { were you by... }\end{aligned}$
$\begin{aligned} & \text { 1. Heavy bleeding during your menstrual period } \\ & \text { all }\end{aligned}$
2. Passing blood clots during your menstrual period
3. Fluctuation in the duration of your menstrual
period compared to your previous cycle
4. Fluctuation in the length of your monthly cycle
compared to your previous cycles
5. Feeling tightness or pressure in your pelvic area
6. Frequent urination during the daytime hours
7. Frequent nighttime urination


The following questions ask about your feelings and experiences regarding the impact of uterine fibroid symptoms on your life. Please consider each question as it relates to your experiences with uterine fibroids during the previous 3 months.

There are no right or wrong answers. Please be sure to answer every question by checking $(\checkmark)$ the most appropriate box. If the question does not apply to you, please check "none of the time" as your option.

\begin{tabular}{lccccc}
\hline $\begin{array}{l}\text { During the previous } 3 \text { months, how often have } \\
\text { your symptoms related to uterine fibroids... }\end{array}$ & $\begin{array}{c}\text { None of } \\
\text { the } \\
\text { time }\end{array}$ & $\begin{array}{c}\text { Alttle } \\
\text { of the } \\
\text { time }\end{array}$ & $\begin{array}{c}\text { Some } \\
\text { of the } \\
\text { time }\end{array}$ of the & $\begin{array}{c}\text { Most } \\
\text { time }\end{array}$ & $\begin{array}{c}\text { All of } \\
\text { the } \\
\text { time }\end{array}$ \\
\hline \hline
\end{tabular}

9. Made you feel anxious about the unpredictable onset or duration of your periods?

10. Made you anxious about traveling?

11. Interfered with your physical activities?

12. Caused you to feel tired or worn out?

13. Made you decrease the amount of time you spent on exercise or other physical activities?

14. Made you feel as if you are not in control of your life?

15. Made you concerned about soiling underclothes?

16. Made you feel less productive?

17. Caused you to feel drowsy or sleepy during the day?

18. Made you feel self-conscious of weight gain?

19. Made you feel that it was difficult to carry out your usual activities?

20. Interfered with your social activities?

21. Made you feel conscious about the size and appearance of your stomach?

22. Made you concerned about soiling bed linen?
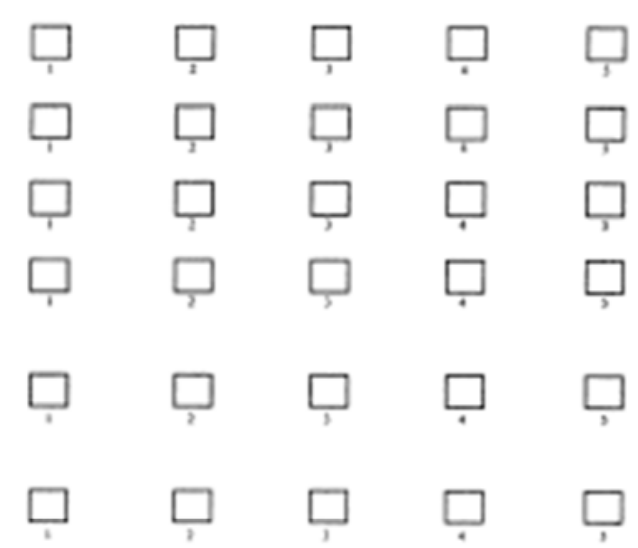


\section{During the previous 3 months, how often have your symptoms related to uterine fibroids...}

23. Made you feel sad, discouraged, or hopeless?

24. Made you feel down hearted and blue?

25. Made you feel wiped out?

26. Caused you to be concerned or worried about your health?

27. Caused you to plan activities more carefully?

28. Made you feel inconvenienced about always carrying extra pads, tampons, and clothing to avoid accidents?

29. Caused you embarrassment?

30. Made you feel uncertain about your future?

31. Made you feel irritable?

32. Made you concerned about soiling outer clothes?

33. Affected the size of clothing you wear during your periods?

34. Made you feel that you are not in control of your health?

35. Made you feel weak as if energy was drained from your body?

36. Diminished your sexual desire?

37. Caused you to avoid sexual relations?

\begin{tabular}{ccccc}
$\begin{array}{c}\text { None of } \\
\text { the little } \\
\text { of the } \\
\text { time }\end{array}$ & $\begin{array}{c}\text { Some } \\
\text { of the } \\
\text { time }\end{array}$ & $\begin{array}{c}\text { Most of the All of } \\
\text { time }\end{array}$ & $\begin{array}{c}\text { the } \\
\text { time }\end{array}$ \\
\hline
\end{tabular}

$\begin{array}{ccccc}\square & \square & \square & \square & \square \\ \square & \square & \square & \square & \square\end{array}$
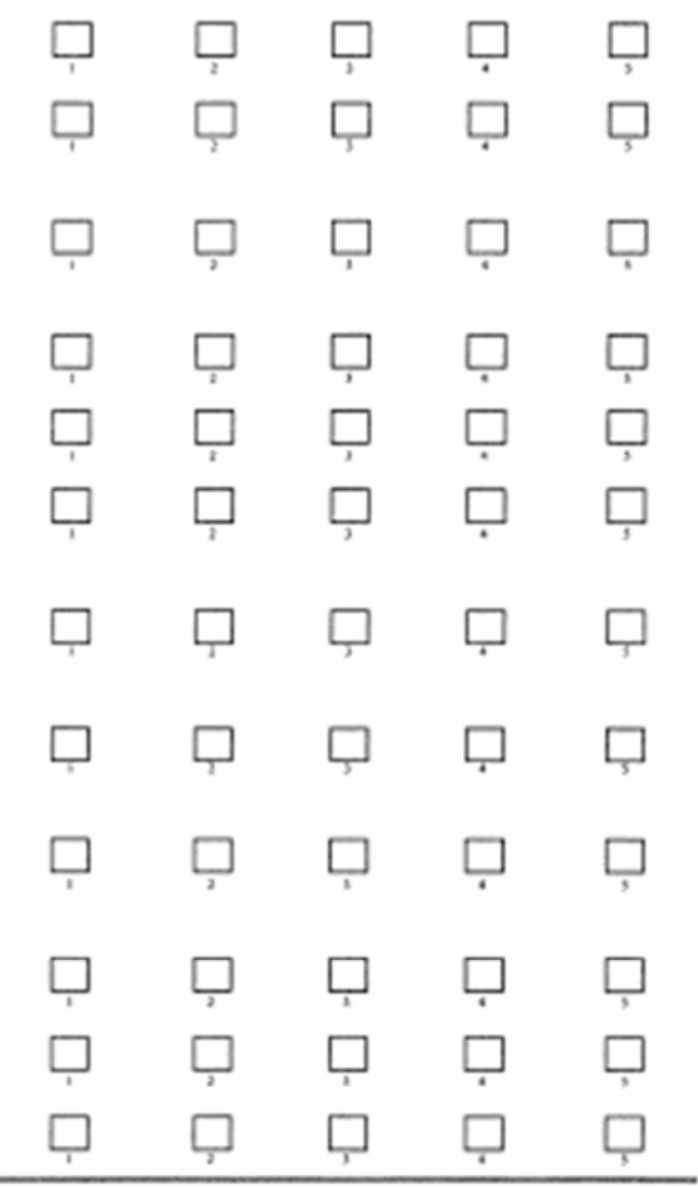


\section{ANEXO III - Traduções juramentadas do UFS-QOL em português}

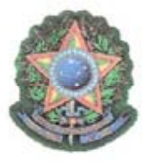

\section{REPÚBLICA FEDERATIVA DO BRASIL Margarida Candida Troncon Busatto}

TRADUTORA PÚBLICA E INTÉRPRETE COMERCIAL PORTUGUÊS -INGLÊS

SWORN TRANSLATOR PORTUGUESE ENGLISH

Matrícula n ${ }^{\circ} 1260$ na Junta Comercial do Estado de São Paulo CPF 037.400.508.70 INSS 1.164.523.539-9 CCM 1052195/01 RG 2.538.222 R. Comandante Marcondes Salgado 866 - ap. 602 - Centro - Ribeirão Preto - SP - CEP 14010-150 Fone/Fax: (16)3635-6444 E-mail mbusatto@uol.com.br

$\begin{array}{lll}\text { Tradução } \mathrm{n}^{\circ} 738 & \text { Livro: } 6 & \text { Folha: } 210 \\ \text { Translation } \# 738 & \text { Book: } 6 & \text { Page: } 210\end{array}$

Eu, MARGARIDA CANDIDA TRONCON BUSATTO, Tradutora Pública para os idiomas Português e Inglês, no Estado de São Paulo, certifico e dou fé, para os devidos fins, que no dia 18 de Fevereiro de 2014, me foi apresentada cópia eletrônica de um Questionário de Qualidade de Vida, em Inglês, a qual traduzo para o vernáculo no seguinte teor:

Apêndice 5 - Questionário UFS-QOL

Rubrica da Paciente

APÊNDICE A

Data:

Carteira de Identidade da Paciente:

\section{QUESTIONÁRIO DE SINTOMA DE FIBRÓIDE UTERINO E QUALIDADE DE VIDA RELACIONADA À SAÚDE}

(UFS-QOL)

Listados abaixo se encontram sintomas experimentados por mulheres portadoras de fibroides uterinos. Considere, por favor, cada sintoma da maneira como este se relaciona com seus fibroides uterinos ou seu ciclo menstrual. Cada questão pergunta quanto incomodo você tem experimentado para cada sintoma durante os últimos 3 meses.

Não há respostas certas ou erradas. Certifique-se, por favor, de responder cada pergunta assinalando $(\checkmark)$ no quadrado mais apropriado. Se a pergunta não se aplica a você, marque a resposta "nem um pouco".

\begin{tabular}{|c|c|c|c|c|c|}
\hline $\begin{array}{l}\text { Durante os últimos } 3 \text { meses, o quanto você } \\
\text { ficou perturbada com... }\end{array}$ & $\begin{array}{c}\text { Nem } \\
\text { um } \\
\text { pouco }\end{array}$ & $\begin{array}{l}\text { Muito } \\
\text { pouco }\end{array}$ & $\underset{\text { pouco }}{\text { Um }}$ & Muito & $\begin{array}{l}\text { Muitis- } \\
\text { simo }\end{array}$ \\
\hline \multirow{2}{*}{$\begin{array}{l}\text { 1. Sangramento intenso durante seu periodo } \\
\text { menstrual }\end{array}$} & 口 & 口 & 口 & $\square$ & 口 \\
\hline & 1 & 2 & 3 & 4 & 5 \\
\hline \multirow{2}{*}{$\begin{array}{l}\text { 2. Eliminação de coágulos durante seu período } \\
\text { menstrual }\end{array}$} & 口 & $\square$ & 口 & ㅁ & ㅁ \\
\hline & 1 & 2 & 3 & 4 & 5 \\
\hline \multirow{2}{*}{$\begin{array}{l}\text { 3. Flutuação na duração de seu período } \\
\text { menstrual comparado ao seu ciclo anterior }\end{array}$} & ㅁ & ㅁ & 口 & ㅁ & 口 \\
\hline & 1 & 2 & 3 & 4 & 5 \\
\hline \multirow{2}{*}{$\begin{array}{l}\text { 5. Sensação de aperto ou pressão em sua região } \\
\text { pélvica }\end{array}$} & 口 & $\square$ & $\square$ & $\square$ & 口 \\
\hline & 1 & 2 & 3 & 4 & 5 \\
\hline \multirow{2}{*}{ 6. Urinação frequente durante as horas do dia } & ㅁ & $\square$ & $\square$ & $\square$ & \\
\hline & 1 & 2 & 3 & 4 & \\
\hline
\end{tabular}




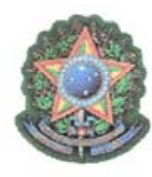

\title{
REPÚBLICA FEDERATIVA DO BRASIL Margarida Candida Troncon Busatto
}

\author{
TRADUTORA PÚBLICA E INTÉRPRETE COMERCIAL \\ PORTUGUÊS -INGLÊS \\ SWORN TRANSLATOR PORTUGUESE - \\ ENGLISH
}

Matrícula n 1260 na Junta Comercial do Estado de São Paulo CPF 037.400.508.70 INSS 1.164.523.539-9 CCM 1052195/01 RG 2.538.222 R. Comandante Marcondes Salgado 866 - ap. 602 - Centro - Ribeirão Preto - SP - CEP 14010-150 Fone/Fax: (16)3635-6444

E-mail mbusatto@uol.com.br

Tradução $\mathrm{n}^{\circ} 738$

Translation \# 738
Livro: 6

Book: 6
Folha: 211

Page: 211

7. Urinação frequente durante a noite

8. Sensação de fadiga

\begin{tabular}{ccccc}
$\square$ & $\square$ & $\square$ & $\square$ & $\square$ \\
1 & 2 & 3 & 4 & 5 \\
$\square$ & $\square$ & $\square$ & $\square$ & $\square$ \\
1 & 2 & 3 & 4 & 5 \\
\hline
\end{tabular}

1

As questões seguintes perguntam sobre seus sentimentos e experiências em relação ao impacto dos sintomas fibroide uterinos em sua vida. Considere, por favor, cada pergunta da maneira como ela se relaciona com suas experiências com fibroides uterinos durante os últimos 3 meses.

Não há respostas certas ou erradas. Certifique-se, por favor, de responder a pergunta assinalando $(\checkmark)$ no quadrado mais apropriado. Se a pergunta não se aplica a você, marque a resposta "nunca".

\begin{tabular}{|c|c|c|c|c|c|}
\hline $\begin{array}{l}\text { Durante os últimos } 3 \text { meses, com que } \\
\text { frequência seus sintomas relacionados aos } \\
\text { fibroides uterinos... }\end{array}$ & Nunca & $\begin{array}{l}\text { Poucas } \\
\text { vezes }\end{array}$ & $\begin{array}{l}\text { Algumas } \\
\text { vezes }\end{array}$ & $\begin{array}{l}\text { A maior } \\
\text { parte do } \\
\text { tempo }\end{array}$ & $\begin{array}{c}\text { O } \\
\text { tempo } \\
\text { todo }\end{array}$ \\
\hline \multirow{2}{*}{$\begin{array}{l}\text { Fizeram com que você se sentisse ansiosa } \\
\text { em relação ao início ou duração } \\
\text { imprevisiveis de seus periodos menstruais? }\end{array}$} & $\square$ & ㅁ & $\square$ & $\square$ & $\square$ \\
\hline & 1 & 2 & 3 & 4 & 5 \\
\hline \multirow{2}{*}{$\begin{array}{l}\text { Fizeram com que você se sentisse ansiosa } \\
\text { em relação a viagens? }\end{array}$} & $\square$ & 口 & $\square$ & $\square$ & $\square$ \\
\hline & 1 & 2 & 3 & 4 & 5 \\
\hline \multirow[t]{2}{*}{ 11. Interferiram em suas atividades fisicas? } & $\square$ & $\square$ & $\square$ & $\square$ & $\square$ \\
\hline & 1 & 2 & 3 & 4 & 5 \\
\hline \multirow{2}{*}{$\begin{array}{l}\text { 12. Fizeram com que você se sentisse cansada } \\
\text { ou exausta? }\end{array}$} & $\square$ & $\square$ & $\square$ & $\square$ & $\square$ \\
\hline & 1 & 2 & 3 & 4 & 5 \\
\hline \multirow{2}{*}{$\begin{array}{l}\text { 13. Fizeram com que você diminuísse a } \\
\text { quantidade de tempo que você usa em } \\
\text { exercícios ou outras atividades fisicas? }\end{array}$} & 口 & ㅁ & $\square$ & $\square$ & 口 \\
\hline & 1 & 2 & 3 & 4 & 5 \\
\hline \multirow{2}{*}{$\begin{array}{l}\text { 14. Fizeram com que você se sentisse como se } \\
\text { não tivesse controle sobre sua vida? }\end{array}$} & 口 & $\square$ & $\square$ & $\square$ & $\square$ \\
\hline & 1 & 2 & 3 & 4 & 5 \\
\hline \multirow{2}{*}{$\begin{array}{l}\text { 15. Fizeram com que você se sentisse } \\
\text { preocupada com roupas de baixo } \\
\text { manchadas? }\end{array}$} & $\square$ & $\square$ & $\square$ & $\square$ & $\square$ \\
\hline & 1 & 2 & 3 & 4 & 5 \\
\hline
\end{tabular}




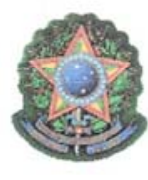

\title{
REPÚBLICA FEDERATIVA DO BRASIL \\ Margarida Candida Troncon Busatto
}

\author{
TRADUTORA PÚBLICA E INTÉRPRETE COMERCIAL \\ PORTUGUÊS -INGLÊS \\ SWORN TRANSLATOR PORTUGUESE -
}

ENGLISH

Matrícula n ${ }^{\circ} 1260$ na Junta Comercial do Estado de São Paulo CPF 037.400.508.70 INSS 1.164.523.539-9 CCM 1052195/01 RG 2.538.222 R. Comandante Marcondes Salgado 866 - ap. 602 - Centro - Ribeirão Preto - SP - CEP 14010-150 Fone/Fax: (16)3635-6444

E-mail mbusatto@uol.com.br

$\begin{array}{lll}\text { Tradução } \mathrm{n}^{\circ} 738 & \text { Livro: } 6 & \text { Folha: } 212 \\ \text { Translation \# } 738 & \text { Book: } 6 & \text { Page: } 212\end{array}$

16. Fizeram com que você se sentisse menos produtiva?

$\begin{array}{lllll}\square & \square & \square & \square & \square \\ 1 & 2 & 3 & 4 & 5 \\ \square & \square & \square & \square & \square \\ 1 & 2 & 3 & 4 & 5 \\ \square & \square & \square & \square & \square \\ 1 & 2 & 3 & 4 & 5 \\ \square & \square & \square & \square & \square \\ 1 & 2 & 3 & 4 & 5 \\ \square & \square & \square & \square & \square \\ 1 & 2 & 3 & 4 & 5 \\ \square & \square & \square & \square & \square \\ 1 & 2 & 3 & 4 & 5 \\ \square & \square & \square & \square & \square \\ 1 & 2 & 3 & 4 & 5\end{array}$

17. Fizeram com que você se sentisse com sono ou sonolenta durante o dia?

18. Fizeram com que você se sentisse desconfortavelmente consciente de ter ganhado peso?

19. Fizeram com que você sentisse que estava dificil efetuar suas atividades habituais?

20. Interferiram em suas atividades sociais?

21. Fizeram com que você se sentisse consciente do tamanho e aparência do seu estomago?

22. Fizeram com que você se sentisse preocupada com roupas de cama manchadas?

2

\begin{tabular}{|c|c|c|c|c|c|}
\hline $\begin{array}{l}\text { Durante os últimos } 3 \text { meses, com que } \\
\text { frequência seus sintomas relacionados aos } \\
\text { fibroides uterinos... }\end{array}$ & Nunca & $\begin{array}{l}\text { Poucas } \\
\text { vezes }\end{array}$ & $\begin{array}{l}\text { Algumas } \\
\text { vezes }\end{array}$ & $\begin{array}{l}\text { A maior } \\
\text { parte do } \\
\text { tempo }\end{array}$ & $\begin{array}{c}0 \\
\text { tempo } \\
\text { todo }\end{array}$ \\
\hline \multirow{2}{*}{$\begin{array}{l}\text { Fizeram com que você se sentisse triste, } \\
\text { desanimada, ou desesperada? }\end{array}$} & 口 & 口 & 口 & $\square$ & 口 \\
\hline & 1 & 2 & 3 & 4 & 5 \\
\hline \multirow{2}{*}{$\begin{array}{l}\text { Fizeram com que você se sentisse } \\
\text { deprimida e abatida? }\end{array}$} & ㅁ & ㅁ & ㅁ & ㅁ & $\square$ \\
\hline & 1 & 2 & 3 & 4 & 5 \\
\hline \multirow{2}{*}{$\begin{array}{l}\text { 25. Fizeram com que você se sentisse } \\
\text { extremamente cansada? }\end{array}$} & 口 & ㅁ & 口 & ㅁ & ㅁ \\
\hline & 1 & 2 & 3 & 4 & 5 \\
\hline \multirow{2}{*}{$\begin{array}{l}\text { 26. Fizeram com que você se sentisse } \\
\text { preocupada ou ansiosa em relação à sua } \\
\text { saúde? }\end{array}$} & ㅁ & 口 & 口 & 口 & 口 \\
\hline & 1 & 2 & 3 & 4 & 5 \\
\hline \multirow{2}{*}{$\begin{array}{l}\text { 27. Fizeram com que você planejasse as } \\
\text { atividades mais cuidadosamente? }\end{array}$} & $\square$ & $\square$ & $\square$ & 口 & 口 \\
\hline & 1 & 2 & 3 & 4 & 5 \\
\hline
\end{tabular}




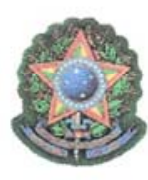

\title{
REPÚBLICA FEDERATIVA DO BRASIL Margarida Candida Troncon Busatto
}

\author{
TRADUTORA PÚBLICA E INTÉRPRETE COMERCIAL \\ PORTUGUÊS -INGLÊS \\ SWORN TRANSLATOR PORTUGUESE -
}

ENGLISH

Matricula no 1260 na Junta Comercial do Estado de São Paulo CPF 037.400.508.70 INSS 1.164.523.539-9 CCM 1052195/01 RG 2.538.222 R. Comandante Marcondes Salgado 866 - ap. 602 - Centro - Ribeirão Preto - SP - CEP 14010-150 Fone/Fax: (16)3635-6444

E-mail mbusatto@uol.com.br

$\begin{array}{lll}\text { Traducão } \mathrm{n}^{\circ} 738 & \text { Livro: } 6 & \text { Folha: } 213 \\ \text { Translation \# } 738 & \text { Book: } 6 & \text { Page: } 213\end{array}$

28. Fizeram com que você se sentisse incomodada por sempre carregar absorventes, tampões e roupas extras para evitar acidentes?

29. Causaram-lhe embaraço?

30. Fizeram com que você sentisse incerteza em relação ao seu futuro?

31. Fizeram com que você se sentisse irritada?

32. Fizeram com que você se sentisse preocupada em relação a roupas exteriores?

33. Afetaram o tamanho das roupas que você usa durante seus períodos menstruais?

34. Fizeram com que você se sentisse sem controle sobre sua saúde?

\begin{tabular}{lllll}
$\square$ & $\square$ & $\square$ & $\square$ & $\square$ \\
1 & 2 & 3 & 4 & 5 \\
$\square$ & $\square$ & $\square$ & $\square$ & $\square$ \\
1 & 2 & 3 & 4 & 5 \\
$\square$ & $\square$ & $\square$ & $\square$ & $\square$ \\
1 & 2 & 3 & 4 & 5 \\
$\square$ & $\square$ & $\square$ & $\square$ & $\square$ \\
1 & 2 & 3 & 4 & 5 \\
$\square$ & $\square$ & $\square$ & $\square$ & $\square$ \\
1 & 2 & 3 & 4 & 5 \\
$\square$ & $\square$ & $\square$ & $\square$ & $\square$ \\
1 & 2 & 3 & 4 & 5 \\
$\square$ & $\square$ & $\square$ & $\square$ & $\square$ \\
1 & 2 & 3 & 4 & 5 \\
$\square$ & $\square$ & $\square$ & $\square$ & $\square$ \\
1 & 2 & 3 & 4 & 5 \\
$\square$ & $\square$ & $\square$ & $\square$ & $\square$ \\
1 & 2 & 3 & 4 & 5 \\
$\square$ & $\square$ & $\square$ & $\square$ & $\square$ \\
1 & 2 & 3 & 4 & 5 \\
\hline
\end{tabular}

35. Fizeram com que você se sentisse fraca, como se a energia tivesse sido drenada de seu corpo?

36. Diminuíram seu desejo sexual?

37. Fizeram com que você evitasse relações sexuais? 


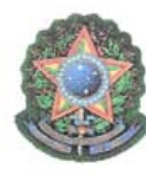

\title{
REPÚBLICA FEDERATIVA DO BRASIL Margarida Candida Troncon Busatto
}

\author{
TRADUTORA PÚBLICA E INTÉRPRETE COMERCIAL \\ PORTUGUÊS -INGLÊS \\ SWORN TRANSLATOR PORTUGUESE - \\ ENGLISH \\ Matrícula n ${ }^{\circ} 1260$ na Junta Comercial do Estado de São Paulo \\ CPF 037.400.508.70 INSS 1.164.523.539-9 CCM 1052195/01 RG 2.538.222 \\ R. Comandante Marcondes Salgado 866 - ap. 602 - Centro - Ribeirão \\ Preto - SP - CEP 14010-150 Fone/Fax: (16)3635-6444 \\ E- mail mbusatto@uol.com.br

$\begin{array}{lll}\text { Tradução } \mathrm{n}^{\circ} 738 & \text { Livro: } 6 & \text { Folha: } 214 \\ \text { Translation \# } 738 & \text { Book: } 6 & \text { Page: } 214\end{array}$

\section{APÊNDICE B} \\ Manual de Pontuação UFS-QoL \\ [SINTOMA DE FIBRÓIDE UTERINO - QUALIDADE DE VIDA]
}

Para calcular a pontuação de um sintoma em relação à gravidade do mesmo, crie uma pontuação somada a partir dos itens listados abaixo e use então a fórmula abaixo da tabela para transformar o valor. Isso fornecerá as pontuações dos sintomas, onde os valores de pontuações mais altas são indicativos de maior gravidade dos sintomas ou incomodo e pontuações mais baixas indicarão a gravidade mínima do sintoma (pontuações altas = ruins).

\begin{tabular}{lccc}
\hline Escala & $\begin{array}{c}\text { Valores da Soma } \\
\text { dos Itens }\end{array}$ & $\begin{array}{c}\text { Pontuações Brutas } \\
\text { Mais Altas e Mais Baixas } \\
\text { Possíveis }\end{array}$ & $\begin{array}{c}\text { Variação Possível de } \\
\text { Pontuações Brutas }\end{array}$ \\
\hline Gravidade do Sintoma & Soma 1 - 8 & 8,40 & 32 \\
\hline
\end{tabular}

Transformação para pontuações brutas de Gravidade de Sintoma SOMENTE:

Pontuação Transformada $=\frac{(\text { Pontuação bruta real }- \text { pontuação bruta mais baixa possivel })}{\text { Possivel variação de pontuação bruta }} \times 100$

Para as Sub-escalas HRQL [Qualidade de Vida Relacionada à Saúde] (preocupação, atividades, energia/humor, controle, constrangimento e função sexual), crie pontuações somadas dos itens listados abaixo para cada sub-escala individual. Para calcular a pontuação total HRQL, some o valor de cada sub-escala individual (não some itens individuais). Use a formula abaixo da tabela para transformar todos os valores. Pontuações mais altas serão indicativas de HRQL melhor (alta = boa).

\begin{tabular}{lccc}
\hline Escala & $\begin{array}{c}\text { Soma dos Valores } \\
\text { dos Itens }\end{array}$ & $\begin{array}{c}\text { Pontuações Brutas } \\
\text { Mais Altas e Mais Baixas } \\
\text { Possíveis }\end{array}$ & $\begin{array}{c}\text { Variação Possível de } \\
\text { Pontuações Brutas }\end{array}$ \\
\hline Preocupação & $9+15+22+28+32$ & 5,25 & 20 \\
Atividades & $10+11+13+19+20+27+29$ & 7,35 & 28 \\
Energia/humor & $12+17+23+24+25+31+35$ & 7,35 & 28 \\
Controle & $14+16+26+30+34$ & 5,25 & 12 \\
Constrangimento & $18+21+33$ & 3,15 & 8 \\
Função sexual & $36+37$ & 2,10 & 116 \\
HRQL TOTAL & Soma de 6 Pontuações de & 29,145 &
\end{tabular}

Sub-escala 


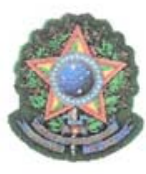

\title{
REPÚBLICA FEDERATIVA DO BRASIL Margarida Candida Troncon Busatto
}

\author{
TRADUTORA PÚBLICA E INTÉRPRETE COMERCIAL \\ PORTUGUÊS -INGLÊS \\ SWORN TRANSLATOR PORTUGUESE - \\ ENGLISH
}

Matrícula $\mathrm{n}^{\circ} 1260$ na Junta Comercial do Estado de São Paulo CPF 037.400.508.70 INSS 1.164.523.539-9 CCM 1052195/01 RG 2.538.222

R. Comandante Marcondes Salgado 866 - ap. 602 - Centro - Ribeirão Preto - SP - CEP 14010-150 Fone/Fax: (16)3635-6444

E- mail mbusatto@uol.com.br

$\begin{array}{lll}\text { Tradução } \mathrm{n}^{\circ} 738 & \text { Livro: } 6 & \text { Folha: } 215 \\ \text { Translation \# } 738 & \text { Book: } 6 & \text { Page: } 215\end{array}$

Formula para transformação de pontuação bruta HRQL SOMENTE:

Pontuação Transformada $=\frac{(\text { Pontuação mais alta possivel }- \text { pontuação bruta real })}{\text { Variação possivel de pontuação bruta }} \quad \times 100$

\section{Itens Ausentes}

Para as análises de sub-escala, se $<50 \%$ dos itens da escala estiverem faltando, a escala deverá ser mantida com a média de pontuação de escala dos itens presentes usados para atribuir uma pontuação aos itens ausentes. Se $\geq 50 \%$ dos itens estiverem faltando, nenhuma pontuação de escala deverá ser calculada, a sub-escala deverá ser considerada ausente. Se uma sub-escala estiver ausente, o HRQL total não poderá ser calculado.

Nada mais consta do documento acima, o qual devolvo com esta tradução, a qual conferi, achei conforme e assino. DOU FÉ.

Ribeirão Preto, 18 de Fevereirqde 2014
Margaui da 6 ! Dusatg

Emolumentos: R\$285,00 Recibo N.440 


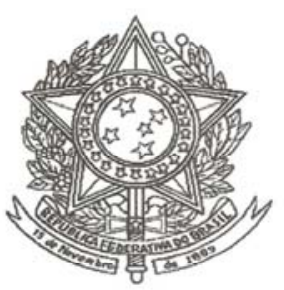

\section{Maria Luíza de Góes Gabarra \\ Tradutora Pública e Intérprete Comercial} Idioma Inglês

Matriculada na Junta Comercial do Estado de São Paulo, sob o n ${ }^{\circ} 1347$, portaria $\mathrm{n}^{\circ} 68 / 2000$, de 12 de junho de 2000.

RG 3.948.766; CPF 743.910.628-87; CCM 981.303-01; INSS 10.617.631.538.

Rua Argeu Fuliotto 25, CEP 14096-520 Ribeirão Preto, SP.

Telefone (16) 624-9155, Fax: (16) 621-4138. E-mail: mlgabarra@ig.com.br

Tradução n: 874

livro: 005

fls 175

Certifico e dou fé, para os devidos fins, que nesta data me foi apresentado um documento no idioma Inglês, com a seguinte identificação: "Uterine Fibroid Symptom and Health - Related Quality of Life Questionnaire" o qual traduzo do Inglês para o vernáculo em 2 páginas, no seguinte teor:

\section{Terceiro Questionário}

APÊNDICE A

Iniciais da Paciente: / Identidade da Paciente:

Data:

Questionário da Qualidade de Vida Relacionada à Saúde e aos Sintomas do Fibroma Uterino (UFSQOL)

Relacionados abaixo estão os sintomas de mulheres que sofrem de fibromas uterinos. Por favor, considere a maneira como cada sintoma se relaciona com seu fibroma uterino ou seu ciclo menstrual. $\mathrm{O}$ objetivo de cada pergunta é saber o quanto cada um desses sintomas tem incomodado você nesses últimos 3 meses.

Não há respostas certas ou erradas. Certifique-se de responder cada pergunta, marcando o quadrinho mais apropriado. Se uma pergunta não se aplicar a você, favor responder "Nem um pouco"

\begin{tabular}{|l|l|l|l|l|l|}
\hline $\begin{array}{l}\text { Durante os 3 últimos meses quanto se sentiu } \\
\text { incomodada por: }\end{array}$ & $\begin{array}{l}\text { Nem um } \\
\text { pouco }\end{array}$ & $\begin{array}{l}\text { Um } \\
\text { tiquinho }\end{array}$ & Um pouco & Bastante & Muitissimo \\
\hline 1- Sangramento forte durante o periodo menstrual & & & & & \\
\hline 2- Ter coágulos de sangue na menstruação & & & & & \\
\hline $\begin{array}{l}\text { 3- Oscilação da duração do seu periodo menstrual } \\
\text { comparado com os anteriores }\end{array}$ & & & & & \\
\hline $\begin{array}{l}\text { 4- Oscilação da duração do seu ciclo menstrual } \\
\text { comparado com os anteriores }\end{array}$ & & & & & \\
\hline $\begin{array}{l}\text { 5- Sentimento de aperto ou pressão na sua área } \\
\text { pélvica }\end{array}$ & & & & & \\
\hline 6- Freqüente vontade de Urinar durante o dia & & & & & \\
\hline 7- Frequente vontade de Urinar durante a noite & & & & & \\
\hline 8- Sentir-se fatigada & & & & & \\
\hline
\end{tabular}

As próximas perguntas questionam sobre seus sentimentos e experiências com relação ao impacto dos sintomas de Fibroma Uterino em sua vida. Por favor, considere cada pergunta na medida em que ela se relaciona com suas experiências de fibroma uterino durante os 3 últimos meses.

Não há resposta certa ou errada. Certifique-se de responder a todas as perguntas marcando no quadro apropriado. Se a questão não se aplicar a você, marque a resposta "nenhum momento". 


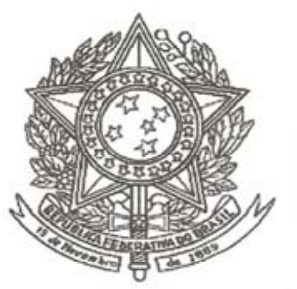

\section{Maria Luíza de Góes Gabarra \\ Tradutora Pública e Intérprete Comercial \\ Idioma Inglês}

Matriculada na Junta Comercial do Estado de São Paulo, sob o n¹347, portaria $\mathrm{n}^{\circ} 68 / 2000$, de 12 de junho de 2000 .

RG 3.948.766; CPF 743.910.628-87; CCM 981.303-01; INSS 10.617.631.538.

Rua Argeu Fuliotto 25, CEP 14096-520 Ribeirão Preto, SP.

Telefone (16) 624-9155, Fax: (16) 621-4138. E-mail: mlgabarra@ig.com.br

Tradução $n^{\circ} 874$

Livro 005

fls 176

\begin{tabular}{|c|c|c|c|c|c|}
\hline $\begin{array}{l}\text { Durante os últimos } 3 \text { meses, qual a frequência que } \\
\text { os sintomas de fibroma uterino: }\end{array}$ & $\begin{array}{l}\text { Em } \\
\text { Nenhum } \\
\text { momento }\end{array}$ & $\begin{array}{l}\text { Pequena } \\
\text { parte do } \\
\text { tempo }\end{array}$ & $\begin{array}{l}\text { Alguma } \\
\text { parte do } \\
\text { tempo }\end{array}$ & 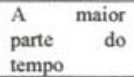 & O tempo todo \\
\hline \multicolumn{6}{|l|}{$\begin{array}{l}\text { 9- A fizeram sentir-se ansiosa sobre a imprevisão da } \\
\text { data ou duração da menstruação? }\end{array}$} \\
\hline \multicolumn{6}{|l|}{ 10- A fizeram sentir-se ansiosa devido a viagem? } \\
\hline \multicolumn{6}{|l|}{ 11- Interferiram com suas atividades fisicas? } \\
\hline \multicolumn{6}{|l|}{ 12- A fizeram sentir-se cansada ou exausta? } \\
\hline \multicolumn{6}{|l|}{$\begin{array}{l}\text { 13- Fizeram você diminuir o tempo que gasta com } \\
\text { exercicios ou atividades fisicas? }\end{array}$} \\
\hline \multicolumn{6}{|l|}{ 14- A fizeram sentir que não controla sua vida? } \\
\hline \multicolumn{6}{|l|}{ 15- A deixaram receosa de manchar a roupa intima? } \\
\hline \multirow{2}{*}{\multicolumn{6}{|c|}{ 16- A fizeram sentir-se menos produtiva? }} \\
\hline \multirow{2}{*}{$\begin{array}{l}\text { 17- A fizeram sentir sono ou tontura durante o dia? } \\
\text { 18-A fizeram sentir-se consciente de ganho de peso? }\end{array}$} & & & & & \\
\hline & & & & & \\
\hline \multicolumn{6}{|l|}{$\begin{array}{l}\text { 19- A fizeram sentir dificuldade em desempenhar } \\
\text { suas atividades usuais? }\end{array}$} \\
\hline \multicolumn{6}{|l|}{ 20- Interferiram com suas atividades sociais? } \\
\hline \multicolumn{6}{|l|}{$\begin{array}{l}\text { 21- A fizeram sentir-se consciente sobre o tamanho } \\
\text { e aparência da sua barriga? }\end{array}$} \\
\hline \multicolumn{6}{|l|}{ 22-A deixaram receosa de manchar roupa de cama? } \\
\hline \multicolumn{6}{|l|}{$\begin{array}{l}\text { 23-A fizeram sentir-se triste, desencorajada ou } \\
\text { desesperada? }\end{array}$} \\
\hline \multicolumn{6}{|l|}{ 24- A fizeram sentir-se melancólica e deprimida? } \\
\hline \multicolumn{6}{|l|}{ 25- A fizeram sentir-se destruida? } \\
\hline \multicolumn{6}{|l|}{ 26- A fizeram sentir-se preocupada com sua saúde? } \\
\hline \multicolumn{6}{|l|}{$\begin{array}{l}\text { 27-A fizeram planejar suas atividades com mais } \\
\text { cuidado? }\end{array}$} \\
\hline \multicolumn{6}{|l|}{$\begin{array}{l}\text { 28. A fizeram sentir o inconveniente de sempre ter } \\
\text { que levar absorventes, tampōes, e roupas extras para } \\
\text { evitar acidentes? }\end{array}$} \\
\hline \multicolumn{6}{|l|}{ 29. Lhe causaram embaraço? } \\
\hline \multicolumn{6}{|l|}{ 30- A fizeram sentir-se insegura sobre seu futuro? } \\
\hline \multicolumn{6}{|l|}{ 31- A fizeram sentir-se irritável? } \\
\hline \multicolumn{6}{|l|}{$\begin{array}{l}\text { 32-A déxaram receosa de manchar roupas } \\
\text { externas? }\end{array}$} \\
\hline \multicolumn{6}{|l|}{$\begin{array}{l}\text { 33- Afetaram o tamanho das roupas que você usa } \\
\text { durante seus periodos menstruais? }\end{array}$} \\
\hline \multicolumn{6}{|l|}{$\begin{array}{l}\text { 34- Fizeram vocế sentir que não está no controle de } \\
\text { sua saúde? }\end{array}$} \\
\hline \multicolumn{6}{|l|}{$\begin{array}{l}\text { 35- Fizeram você se sentir fraca, como se a energia } \\
\text { estivesse sendo drenada de seu corpo? }\end{array}$} \\
\hline \multicolumn{6}{|l|}{ 36- Diminuiram seu desejo sexual? } \\
\hline 37- A levaram a evitar relações sexuais? & & & & & \\
\hline
\end{tabular}

Nada mais consta do documento acima que devolvo com esta tradução datilografada em 2 folhas, as quais conferi, achei conforme, e assino. DOU FÉ.

Emolumentos: R\$ 163,00

Rec. $n^{\circ} 482$

Ribeirão Pfeto, 20 de fefrereiro de 2014.

hanà unade falorea Maria Luiza de Góes Gabarra Tradutora Publica 


\section{ANEXO IV - Autorização de publicação do artigo no São Paulo Medical Journal}

\section{São Paulo Medical Journal - Decision on Manuscript ID SPMJ-2016-0223.R1}

São Paulo Medical Journal <onbehalfof+palotufothu.usp.br@manuscriptcentral.com> para mim, Ibrito *

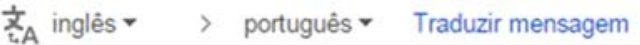

\section{7-Sep-2016}

Dear Prof. Brito:

Manuscript ID SPMJ-2016-0223.R1 entitled "Validation and translation of the Uterine Fibroid Symptom and Quality of Life (UFS-QOL) questionnaire for Brazilian Portuguese language" which you submitted to the São Paulo Medical Journal, has been reviewed. The comments of the reviewer(s) are included at the bottom of this letter.

The reviewer(s) have recommended publication, but also suggest some revisions to your manuscript. Therefore, I invite you to respond to the reviewer(s)' comments and revise your manuscript.

To revise your manuscript, log into https://mc04 manuscriptcentral.com/spmi-scielo and enter your Author Center, where you will find your manuscript title listed under "Manuscripts with Decisions." Under "Actions," click on "Create a Revision." Your manuscript number has been appended to denote a revision.

You may also click the below link to start the revision process (or continue the process if you have already started your revision) for your manuscript. If you use the below link you will not be required to login to ScholarOne Manuscripts.

https://mc04 manuscriptcentral.com/spmj-scielo?URL_MASK=a3d079fd93c047c387c15c1f93232e12

You will be unable to make your revisions on the originally submitted version of the manuscript. Instead, revise your manuscript using a word processing program and save it on your computer. Please also highlight the changes to your manuscript within the document by using the track changes mode in MS Word or by using bold or colored text.

Once the revised manuscript is prepared, you can upload it and submit it through your Author Center. 
SPMJ-2016-0223

ORIGINAL ARTICLE

Validation and translation of the Uterine Fibroid Symptom and Quality of Life (UFS-QOL) questionnaire for Brazilian Portuguese language

Validação e tradução do questionário Uterine Fibroid Symptom and Quality of Life (UFS-QOL) para a língua portuguesa

\section{ABSTRACT}

CONTEXT AND OBJECTIVE: Uterine fibroids (UF) are the most prevalent gynecological tumors. The Uterine Fibroids Symptoms and Quality of Life (UFS-QOL) is the only specific questionnaire that assesses the intensity of symptoms and quality-of-life issues for women with symptomatic UF; however, we do not have its translation in another language than English. Thus, we aimed to translate and culturally validate the UFS-QOL questionnaire for Brazilian Portuguese language.

DESIGN AND SETTING: Cross-sectional study, Department of Gynecology and Obstetrics, FMRP-USP.

METHODS: 113 patients with UF and 55 patients without UF (control group) were interviewed with the UFS-QOL questionnaire after translation and cultural adaptation; the Short-Form 36 questionnaire (SF36) was used as a control questionnaire. Demographic and psychometric variables were analyzed.

RESULTS: Women with UF presented a higher mean of age, body mass index, weight, parity and comorbidities than the control group $(\mathrm{P}<0.05)$. The most prevalent symptoms were abnormal uterine bleeding (93.8\%), pelvic pain (36.3\%) and extrinsic compression (10.6\%) and they presented adequate construct validity with the UFS-QOL severity index (P $<0.05)$. The UFS-QOL presented good internal consistency in severity symptoms and HRQL scores $($ ICC $=0.82 / 0.88)$. Test-retest did not differ among all subscales of the UFS-QOL questionnaire $(\mathrm{P}>.05)$. Structural validity presented correlation indices ranged from 0.590.91. After treatment, women with UF presented an improvement in all UFS-QOL subscales. 
CONCLUSION: The UFS-QOL presented an adequate translation and cultural validation to the Brazilian Portuguese language, with good internal consistency, discriminant validity, construct validity, structural validity, test-retest and responsiveness.

KEY WORDS:. Leiomyoma. Validation studies [publication type]. Translations. Quality of life.

\section{RESUMO}

CONTEXTO E OBJETIVO: O leiomioma uterino (LU) é o tumor ginecológico mais comum na mulher. Existe apenas um questionário que avalia a qualidade de vida de mulheres com esta doença, o Uterine Fibroid Symptom and Quality of Life (UFS-QOL), porém somente na língua inglesa. Dessa forma, objetivamos traduzir e validar culturalmente o questionário UFS-QOL para mulheres brasileiras.

TIPO DE ESTUDO E LOCAL: Estudo transversal, Departamento de Ginecologia e Obstetrícia da FMRP-USP.

MÉTODOS: 113 pacientes portadoras de LU (grupo caso) e 55 pacientes-controle foram entrevistadas com o questionário UFS-QOL após tradução e adaptação cultural. O questionário Short Form-36 foi utilizado para controle. Variáveis demográficas e psicométricas dos questionários foram analisadas.

RESULTADOS: As mulheres com LU uterino apresentaram maior média de idade, IMC, peso, paridade e comorbidades do que no grupo controle $(\mathrm{P}<0.05)$. O sangramento uterino anormal foi a queixa mais prevalente $(93,8 \%)$, seguida de dor pélvica $(36,3 \%)$ e compressão extrínseca (10,6\%) e tais queixas apresentaram adequada validade de constructo com a severidade do UFS-QOL (P < 0.05). O UFS-QOL apresentou adequada consistência interna com a severidade dos sintomas e com os domínios relacionados a qualidade de vida (ICC = 0.82/0.88). A validade estrutural mostrou coeficientes de correlação variando de 0,59 até 0,91. O teste-reteste não diferiu entre as subscalas do UFS-QOL. Depois do tratamento, as mulheres com LU apresentaram melhora em todas as subscalas do UFS-QOL.

CONCLUSÃO: O questionário UFS-QOL para a língua portuguesa apresentou adequada tradução, boa consistência interna, validade de constructo/discriminatória, estrutural e responsividade, assim como adequado teste-reteste.

PALAVRAS-CHAVE: Leiomioma. Estudos de validação. Tradução. Qualidade de vida. 


\section{INTRODUCTION}

Uterine fibroids (UF) are the most common gynecological tumors and are originated from the smooth muscle cells of the uterine wall. Sixty to eighty percent of women present these tumors; ${ }^{1}$ however, 20 to 30\% present symptoms, such as abnormal uterine bleeding and pelvic pain. ${ }^{2}$ In Brazil, there is no accurate data for this disease; however, the number of hysterectomies in this country has stabilized ${ }^{3}$ and clinical management of UF is still a challenge. ${ }^{4}$

An observational study showed that UF patients presented a negative impact of the disease on their quality of life. ${ }^{5}$ They showed social and professional limitations, fear, disbelief and discouragement toward their symptoms, reasons that strengthen their will to undergo hysterectomy. ${ }^{6}$ Given that, the impact of the UF symptoms in women's health-related quality of life (HRQL) is the main indication for treatment and the use of questionnaires may measure the impact of symptoms and the result of clinical and/or surgical interventions. Fourteen years ago, it was published the only questionnaire directed to UF, the Uterine Fibroid Symptom and Quality of Life (UFS-QOL). ${ }^{7}$ The responsiveness of this questionnaire was posteriorly assessed ${ }^{8}$ and his validation occurred in a non-randomized, prospective study. ${ }^{9}$ Therefore, most of the studies that investigated UF have been using this questionnaire.

To our knowledge, we did not find in the literature any cultural translation/validation of the UFS-QOL in the Brazilian Portuguese language. A simple translation is not valid to be used because it is already known that adapting questionnaires to the local language is a difficult task. ${ }^{10}$ Moreover, regional expressions should be incorporated and it is necessary to perform a study to confirm the cultural validation of the questionnaire.

\section{OBJECTIVE}

The authors aimed to translate and culturally validate the UFS-QOL questionnaire for Brazilian Portuguese language.

\section{METHODS}

\section{Type of study and patients}


A cross-sectional study was performed at the Gynecological Surgery Clinic from Hospital das Clínicas da Faculdade de Medicina de Ribeirão da Universidade de São Paulo (HCFMRP-USP) between April and September 2015. Women were recruited by the consultations that are provided in this setting and are treated with clinical or surgical management. The control group was constituted by women from other outpatient gynecological clinics from HCFMRP-USP that did not present abnormal uterine bleeding or pelvic pain as main complaints. Inclusion criteria were: women during reproductive period with UF complaining of abnormal uterine bleeding or pelvic pain or sensation of external compression. We excluded pregnant women or that were using anticoagulant or abnormal uterine bleeding with other secondary causes (endometrial, ovulatory), patients with cognitive impairment or women that didn't know how to read. One hundred and thirteen women comprised the study group and 55 women were the control group, totaling 168 patients. We had five refusals to participate and twelve women were excluded from the study (due to cognitive incapacity to understand the questionnaire) during the enrollment period. All participants signed an informed consent statement and this study was approved by our Institutional Review Board (process number 531.584). This study was elaborated according to the ethical guidelines of the 1975 Declaration of Helsinki.

\section{UFS-QOL questionnaire: translation and validation}

UFS-QOL is a specific questionnaire that assesses the severity of symptoms (8 questions) and the HRQL of women (29 questions) with UF. This latter subscale comprises the following subscales: concern, activities, energy/mood, control, self-conscious and sexual function. ${ }^{7}$ All answers have five options according to a Likert scale. The higher the score of the severity subscale of the questionnaire, symptoms are severe; the smaller the HRQL subscales, poorer is the quality of life.

After obtaining a writtenauthorization from the Society for Interventional Radiology and Prof. James Spies to translate and validate UFS-QOL, the translation was initially performed by two notarized bilingual professors. This translation was evaluated by a committee composed by three gynecologists (L.G.O.B; D.A.M.L; M.A.F.A) and pilot- tested with ten women attended in the outpatient setting; patients were interrogated about any difficulties to the comprehension of the questionnaire. Some words were adapted to ease the understanding by the interviewer. Changes were revised again by the same medical committee 
and the final version was released for application. Back translation was performed by a English native speaker who has knowledge in Portuguese language and the questionnaire was sent to the first author of the questionnaire and to the Society for Interventional Radiology to evaluate. ${ }^{11}$

There were no standardization to the mode of application of the questionnaire (oral interview or self-application); however, most of the questionnaires were auto-filled out by the patient with the option to ask for help to the interviewer if any questions aroused during the reading.

Moreover, SF-36 questionnaire was utilized as a control in order to be compared with the UFS-QOL to calculate construct validity. It measures HRQL using eight domains: vitality, physical functioning, bodily pain, general health perceptions, physical role functioning, emotional role functioning, social role functioning, mental health ${ }^{12}$. Individual items from each subscale are combined to form a subscale score and transformed from 0 to 100. Higher scores indicate better HRQL. ${ }^{13}$

\section{Variables}

Demographic data were obtained: age, weight, height, body mass index (BMI), gravidity, parity, comorbidities. The following clinical symptoms were investigated: presence of abnormal uterine bleeding (AUB), pelvic pain (PP) and sensation of external compression. With regard to psychometric properties for measuring questionnaires, the analyzed variables were: internal consistency, construct validity, test-retest and responsiveness. Internal consistency assesses the correlation between the items and is determined by the subscale and total scores. A higher value indicates a higher correlation among several items from the scales, that is, one or several items may be measuring the same concept. Values over 0.70 were considered adequate or acceptable. ${ }^{14}$ Construct validity was calculated comparing the symptoms with the response of UFS-QOL scores and is considered adequate when different responses are perceived between the groups with and without symptoms. Structural validity was explored by principal component analysis (PCA), with standardized coefficients comparing all questions from each quality of life subscale with the severity subscale in order to identify the highest correlation coefficient. It is important to say that this psychometric analysis was previously done by Spies et al. ${ }^{7}$ to individualize the subscales. Retest $(n=20)$ was performed 1-2 weeks after first application of the questionnaire. Responsiveness $(n=44)$ 
was performed after three months of clinical and/or surgical treatment to assess if UFS-QOL scores were modified after the first application of the questionnaire.

\section{Statistical analysis}

Data were tabulated in Microsoft Excel (Richmond, VA, USA) and statistical analysis was performed by Intercooled Stata 13.0 (College Station, TX, USA). A significance level of $5 \%$ was stipulated in all two-sided tests. Normality analysis was performed by Shapiro-Wilk test and a parametric distribution was found after testing continuous variables (age, body mass index, weight). Chi-square test was used for binomial variables and Student t-test for continuous variables. Power calculation was not performed due to the extense variability of suggested formulae for generating the minimum amount of subjects for a determined research that involves validating and translating a standardized questionnaire ${ }^{10}$.Internal consistency was calculated by Cronbach's alpha (over 0.9 - excellent; 0.7-0.9 - acceptable to good; 0.60.7 - questionable; 0.5-0.6 - poor; below 0.5 - unacceptable) and item-correlation. Structural validity was calculated by a SEM (structural equation modeling) between severity and other quality of life subscales. Test-retest and responsiveness were calculated by paired t-test with extraction of mean with standard deviation and mean difference between variables. Missing data was not treated by imputation methods. No patients answered both questionnaires with less than $50 \%$ of unanswered questions.

\section{RESULTS}

Demographic data are described in Table 1. Women with UF presented a higher mean age $(42.6 \pm 6.5$ years; $\mathrm{P}<.005)$, weight $(78.9 \pm 16.7 \mathrm{~kg})$, BMI $\left(30.3 \pm 6 \mathrm{~kg} / \mathrm{m}^{2} ; \mathrm{P}=.01\right)$, parity $(\mathrm{P}<.005)$ and a statistical trend to present more comorbidities $(53.1 \%$ versus $38.2 \%$; $\mathrm{P}$ $=$.069) than the control group. Most common diseases from the study group were arterial hypertension and anxiety/depressive disorders. With regard to the clinical symptoms, abnormal uterine bleeding was the most prevalent (93.8\%), followed by pelvic pain (36.3\%) and external compression (10.6\%).

Table 2 shows the analysis of the UFS-QOL and SF-36 scores in both groups. All UFS-QOL subscales showed statistically significant differences between women with UF and controls $(\mathrm{P}<.05)$. Women with UF presented higher score in severity and lower scores in the 
subscales that measured quality of life when compared to the control. The self-conscious and sexual function subscales presented a higher reduction in mean difference score from women with uterine fibroids when compared to others. With the regard to the SF-36 domains, women with UF presented a lower quality of life $(\mathrm{P}<.05)$, except for the vitality domain $(\mathrm{P}=.07)$. Given that, a discriminant validity could be demonstrated.

Internal consistency was calculated for UFS-QOL at Table 3 and values over .75 were found for all its subscales and HRQL score at control and study groups, showing an adequate concordance. Item-correlation presented moderate concordance on symptom severity; similarly, at the study group, moderate concordance was seen at the symptom severity, self-conscious and sexual function. Construct validity showed statistical significance between the presence of symptoms and a higher mean UFS-QOL severity score (Table 4). With regard to responsiveness, all UFS-QOL subscales presented an improvement in their quality of life and a reduction in the severity symptoms after treatment (Table 5). The analysis of standardized coefficients of the QoL subscales with severity as a covariance ranged from $0.59-0.91$, as seen in Table 6 . The covariance analysis with severity showed a higher correlation with the following subscales: concern (0.91), control (0.80) and selfconscious (0.81). Finally, no differences were noted in test-retest of the UFS-QOL version for the Brazilian Portuguese language (Table 7) and the final version is presented with this manuscript (Annex).

\section{DISCUSSION}

This study showed that UFS-QOL strongly correlated with symptoms from women with UF with lower HRQL subscales and higher severity score, impacting at women's quality of life. No differences with regard to the ICC were seen among the UFS-QOL subscales in women with UF, despite item correlation were moderate among symptom severity, selfconscious and sexual function. These data are similar to the validation studies performed by Spies et al. ${ }^{7,9}$ Moreover, women with UF presented a worse quality of life when analyzed by the SF-36 questionnaire, except for the vitality domain. This may point out that UFS-QOL is fulfilling its task to be targeting women with UF.

With regard to the structural validity of UFS-QOL, we prepared a SEM (Structural Equation Modeling) comparing the severity subscale with the other subscales to extract which of them presented a higher correlation coefficient. We did not analyze all possibilities because 
this was already performed by Spies et al. ${ }^{7}$ when they published UFS-QOL in English language. Usually, structural validity is prepared when the questionnaire is initially launched to prove that the questions are correctly divided into the better-fit subscales.

Our test-retest reliability demonstrated after paired t-test that no systematic difference was perceived after a range of 1-2 weeks to the second visit. This is similar to what Spies et al. ${ }^{7}$ have found with 27 patients and they did not consider the sample size underpowered to detect differences in baseline characteristics. Our total sample size was higher than the first publication of this questionnaire and we also agree with Spies et al. ${ }^{7}$ that women with UF present epidemiological features that would be difficult to create a similar control group due to its high prevalence.

Furthermore, the UFS-QOL for Brazilian Portuguese language has also demonstrated responsiveness to change among women treated with medications or surgery, with mean change scores greater than 20 points for all subscales. Despite forty patients were included, these data are supported by Harding et al. ${ }^{8}$ that analyzed 102 patients treated with MRI-guided focused ultrasound thermal ablation (MRgFUS) for UF and by larger studies such as the Fibroids Registry Outcomes for Outcomes Data (FIBROID), a database that studied over 2,000 women undergoing uterine embolization for leiomyomata. ${ }^{15}$

To our knowledge, this is the first translation and validation study from UFS-QOL in a different language than English after performing a PUBMED search. Recently, UFS-QOL was slightly modified to women that have performed hysterectomy. ${ }^{16}$ Non-American countries have utilized this questionnaire for studies in women with UF without validating it, like this study performed in Korea. ${ }^{17}$

This study presented some limitations: we did not calculate the criterion validity, which consists of the assessment of UFS-QOL with a clinical tool considered gold standard; in this case, we would have to compare it with the alkaline hematin technique to quantify blood loss, or pictorial blood assessment chart (PBAC). Moreover, despite the control and study groups were different with regard to age and comorbidities, we do not believe that these variables caused a great impact in our results, similarly to Spies et al. ${ }^{7}$

We believe that we met our goal of confirming that the UFS-QOL could be translated without impairment to our language, that is, the Brazilian Portuguese version would be adequate to identifying women with UF in the same way it would do in English-speaking countries. Our expectation is that the validation and translation of this questionnaire will be 
very useful as a tool to measure the impact of symptoms and the results of the interventions related with UF in our country and will strengthen future data produced in our setting.

\section{CONCLUSION}

The Brazilian Portuguese version of the UFS-QOL is a valid and reliable instrument to assess the HRQL of women with UF and demonstrated good internal consistency, discriminant validity, construct validity, structural validity, test-retest and responsiveness.

\section{REFERENCES}

1. Drayer JM, Catherino WH. Prevalence, morbidity and current medical management of uterine leiomyomas. Int J Gynaecol Obstet. 2015;131(2):117-22.

2. Moroni R, Vieira C, Ferriani R, Candido-dos-Reis F, Brito L. Pharmacological treatment of uterine fibroids. Ann Med Health Sci Res. 2014;4(Suppl 3):S185-92.

3. DATASUS. Sistema de Informações Hospitalares do SUS (SIH/SUS): Banco de Dados. Available from: http://tabnet.datasus.gov.br/cgi/sih/midescr.htm. Accessed in 2016 (Aug 25).

4. $\quad$ Stewart EA. Clinical Practice. Uterine fibroids. N Engl J Med. 2015;372(17):1646-55.

5. Brito LG, Panobianco MS, Sabino-de-Freitas MM, et al. Uterine leiomyoma: understanding the impact of symptom on women's lives. Reproductive Health. 2014;11(1):10.

6. Brito LG, Panobianco MS, de Azevedo GD, et al. Motivational factors for women undergoing hysterectomy for uterine leiomyoma. Acta Obstet Gynecol Scand. 2013;92(11):1337-8.

7. Spies JB, Coyne K, Guaou Guaou N, et al. The UFS-QOL, a new disease-specific symptom and health-related quality of life questionnaire for leiomyomata. Obstet Gynecol. 2002;99(2):290-300. 
8. Harding G, Coyne KS, Thompson CL, Spies JB. The responsiveness of the uterine fibroid symptom and health-related quality of life questionnaire (UFS-QOL). Heath Qual Life Outcomes. 2008;6:99.

9. Coyne KS, Margolis MK, Bradley LD, et al. Further validation of the uterine fibroid symptom and quality-of-life questionnaire. Value Health. 2012(1):135-42.

10. Kottner J, Audigé L, Brorson S, et al. Guidelines for reporting reliability and agreement studies (GRRAS) were proposed. J Clin Epidemiol. 2011;64(1):96-106.

11. Beaton DE, Bombardier C, Guillemin F, Ferraz MB. Guidelines for the process of cross-cultural adaptation of self-report measures. Spine 2000;25(24):3186-91.

12. Ciconelli RM, Ferraz MB, Santos W, Meinao I, Quaresma MR. Tradução para a língua portuguesa e validação do questionário genérico de avaliação de qualidade de vida SF36 [Brazilian-Portuguese version of the SF-36. A reliable and valid quality of life outcome measure]. Rev Bras Reumatol. 1999;39(3):143-50.

13. Ware JE Jr, Sherbourne CD. The MOS 36-item-short-form health survey (SF-36). Med Care. 1992;30(6):473-83.

14. Cronbach LJ. Coefficient alpha and the internal structure of tests. Psychometrika 1951;16(3):297-334.

15. Spies JB, Myers ER, Worthington-Kirsch R, et al. The FIBROID Registry: symptom and quality-of-life status 1 year after therapy. Obstet Gynecol. 20015;106(6):1309-18.

16. Coyne KS, Margolis MK, Murphy J, Spies J. Validation of the UFS-QOLhysterectomy questionnaire: modifying an existing measure for comparative effectiveness research. Value Health. 2012;15(5):674-9.

17. Lee JS, Hong GY, Park BJ, Kim TE. Ultrasound-guided high-intensity focused ultrasound treatment for uterine fibroid \& adenomyosis: a single center experience from the Republic of Korea. Ultrason Sonochem. 2015;27:682-7. 
Table 1. Demographic and clinical baseline characteristics

\begin{tabular}{|c|c|c|c|}
\hline Variables & Control $(n=55)$ & Study $(n=113)$ & P-value \\
\hline Age (mean \pm standard deviation) & $37.9(8.2)$ & $42.6(6.5)$ & $<0.005$ \\
\hline Gravidity (median/range) & $1(0-6)$ & $2(0-6)$ & $<0.005$ \\
\hline Parity (median/range) & $1(0-5)$ & $2(0-6)$ & $<0.005$ \\
\hline Educational level (n, \%) & & & $<0.005$ \\
\hline $0-6$ years & $15(27.3)$ & $44(38.9)$ & \\
\hline $7-12$ years & $21(38.2)$ & 63 (55.9) & \\
\hline$>12$ years & $18(32.7)$ & $3(2.6)$ & \\
\hline Not informed & $1(1.8)$ & $3(2.6)$ & \\
\hline $\begin{array}{l}\text { Body mass index (mean } \pm \text { standard } \\
\text { deviation) }\end{array}$ & $27.7(5.8)(\mathrm{n}=54)$ & $30.3(6.0)(n=110)$ & 0.010 \\
\hline Comorbidities (n, \%) & $21(38.18)$ & $60(53.1)$ & 0.069 \\
\hline \multicolumn{4}{|l|}{ Symptoms } \\
\hline Abnormal uterine bleeding & $1(1.8)$ & $106(93.8)$ & $<0.005$ \\
\hline Pelvic pain & $3(5.5)$ & $41(36.3)$ & $<0.005$ \\
\hline External compression & $1(1.8)$ & $12(10.6)$ & $<0.005$ \\
\hline
\end{tabular}


Table 2. Discriminant validity of the Uterine Fibroid Symptom and Quality of Life (UFSQOL) and Short-Form-36 (SF-36) questionnaires from women with uterine fibroids and control patients

\begin{tabular}{|c|c|c|c|}
\hline \multirow[t]{3}{*}{ Questionnaires } & \multicolumn{2}{|c|}{ Mean (SD) } & \multirow[t]{2}{*}{ P-value } \\
\hline & Control & Study & \\
\hline & $(n=55)$ & $(n=113)$ & \\
\hline \multicolumn{4}{|l|}{ UFS-QOL } \\
\hline Symptom severity & $15.7(17.6)$ & $59.4(19.1)$ & $<0.001$ \\
\hline Concern & $95.2(10.9)$ & $33.6(28.7)$ & $<0.001$ \\
\hline Activities & $96.5(10.6)$ & $53.8(26.0)$ & $<0.001$ \\
\hline Energy/Mood & $92.9(18.6)$ & $47.3(28.5)$ & $<0.001$ \\
\hline Control & $94.5(16.2)$ & $51.3(27.3)$ & $<0.001$ \\
\hline Self-conscious & $94.7(16.2)$ & $49.3(25.7)$ & $<0.001$ \\
\hline Sexual function & $90.7(23.8)$ & $43.9(36.6)$ & $<0.001$ \\
\hline Total Score & $361.7(73.7)$ & $115.7(116.9)$ & $<0.001$ \\
\hline \multicolumn{4}{|l|}{ SF-36 } \\
\hline Physical functioning & $74.9(32.3)$ & $59.2(29.6)$ & 0.0021 \\
\hline Physical role functioning & $73.2(39.0)$ & $38.3(44.9)$ & $<0.001$ \\
\hline Bodily pain & $62.5(26.2)$ & $52.0(28.4)$ & 0.023 \\
\hline General health perceptions & $58.6(17.9)$ & $50.5(20.2)$ & 0.013 \\
\hline Vitality & $56.9(21.7)$ & $49.6(25.8)$ & 0.072 \\
\hline Social role functioning & $74.8(30.7)$ & $59.9(32.0)$ & 0.003 \\
\hline Emotional role functioning & $72.7(40.1)$ & $44.8(44.5)$ & $<0.001$ \\
\hline Mental health & 60.7 (21.5) & $50.8(26.5)$ & 0.017 \\
\hline
\end{tabular}


Table 3. Internal consistency (ICC) and item-correlation of women with uterine fibroids and control group

\begin{tabular}{|c|c|c|c|c|}
\hline \multicolumn{5}{|l|}{ UFS-QOL } \\
\hline & \multicolumn{2}{|c|}{ Control $(n=55)$} & \multicolumn{2}{|c|}{ Study $(n=113)$} \\
\hline & $\begin{array}{c}\text { Item- } \\
\text { correlation }\end{array}$ & $\begin{array}{c}\text { Cronbach's } \\
\text { alpha }\end{array}$ & Item correlation & $\begin{array}{c}\text { Cronbach's } \\
\text { alpha }\end{array}$ \\
\hline $\begin{array}{c}\text { Symptom } \\
\text { severity }\end{array}$ & 0.59 & 0.84 & 0.65 & 0.82 \\
\hline Concern & 0.84 & 0.84 & 0.80 & 0.80 \\
\hline Activities & 0.89 & 0.83 & 0.81 & 0.81 \\
\hline Energy/mood & 0.96 & 0.81 & 0.86 & 0.80 \\
\hline Control & 0.92 & 0.82 & 0.86 & 0.80 \\
\hline Self-conscious & 0.90 & 0.82 & 0.66 & 0.82 \\
\hline Sexual function & 0.90 & 0.80 & 0.72 & 0.81 \\
\hline HRQL score & 1.00 & 0.91 & 1.00 & 0.88 \\
\hline
\end{tabular}

UFS-QOL = Uterine Fibroid Symptom and Quality of Life; HRQL = health related quality of life. 
Table 4. Construct validity between uterine fibroid symptoms and the Uterine Fibroid Symptom and Quality of Life (UFS-QOL) questionnaire

\begin{tabular}{|l|l|l|l|l|l|l|l|}
\hline & \multicolumn{2}{|l|}{ Study group } & \multicolumn{2}{l|}{ Control group } & & & \\
\hline & \multicolumn{2}{|c|}{ Mean \pm standard deviation } & & Mean difference & P-value \\
Abnormal uterine & $59.57 \pm 19.92$ & & $19.67 \pm 20.10$ & & -39.9 & & $<0.001$ \\
bleeding & & & & & & \\
\hline Pelvic pain & $60.51 \pm 20.15$ & & $39.61 \pm 28.02$ & & -20.89 & & $<0.001$ \\
\hline External compression & $56.00 \pm 23.74$ & & $44.17 \pm 27.88$ & & -11.83 & & 0.014 \\
\hline
\end{tabular}


Table 5. Responsiveness of women with uterine fibroids after treatment $(n=44)$

UFS-QOL = Uterine Fibroid Symptom and Quality of Life; HRQL = health related quality of life.

\begin{tabular}{|c|c|c|c|c|}
\hline & $\begin{array}{c}\text { Before } \\
\text { treatment }\end{array}$ & $\begin{array}{c}\text { After } \\
\text { treatment }\end{array}$ & & \\
\hline UFS-QOL & \multicolumn{2}{|c|}{ Mean/standard deviation } & Mean difference & P-value \\
\hline Symptom severity & 54.97 (14.57) & 15.05 (17.91) & -39.91 & $<0.005$ \\
\hline Concern & 32.84 (24.97) & 86.59 (24.97) & +53.75 & $<0.005$ \\
\hline Activities & $57.95(24.96)$ & $91.72(13.81)$ & +33.76 & $<0.005$ \\
\hline Energy/mood & 50.08 (28.37) & 83.76 (22.69) & +33.69 & $<0.005$ \\
\hline Control & $54.32(26.86)$ & $87.61(20.50)$ & +33.29 & $<0.005$ \\
\hline Self-conscious & 50.95 (22.68) & 75.19 (27.70) & +24.24 & $<0.005$ \\
\hline Sexual function & $43.18(36.21)$ & 65.91 (39.19) & +22.72 & $<0.005$ \\
\hline HRQL score & $124.42(108.26)$ & 298.09 (110.96) & +173.68 & $<0.005$ \\
\hline
\end{tabular}

UFS-QOL = Uterine Fibroid Symptom and Quality of Life; HRQL = health related quality of life. 
Table 6. Structural validity from all quality of life subscales with the severity scale of the UFS-QOL by structural equation modeling

\begin{tabular}{|c|c|c|}
\hline $\begin{array}{l}\text { UFS-QOL questionnaire (model } \\
\text { subscales with the severity subscale) }\end{array}$ & $\begin{array}{l}\text { Standardized } \\
\text { coefficient (Std error) }\end{array}$ & Variance \\
\hline \multicolumn{3}{|l|}{ Concern (last 3 months) } \\
\hline Anxious about unpredictable onset/duration of periods (Q9) & $0.78(0.031)$ & 0.38 \\
\hline Soiling underclothes (Q15) & $0.91(0.015)$ & 0.16 \\
\hline Soiling bed linen (Q22) & $0.88(0.018)$ & 0.21 \\
\hline Feel inconvenienced about carrying extra pads (Q28) & $0.67(0.044)$ & 0.54 \\
\hline Soiling outer clothes (Q32) & $0.91(0.015)$ & 0.15 \\
\hline \multicolumn{3}{|l|}{ Activities (last 3 months) } \\
\hline Anxious about traveling (Q10) & $0.62(0.050)$ & 0.60 \\
\hline Interfered with physical activities (Q11) & $0.77(0.036)$ & 0.39 \\
\hline Decreased amount time on exercise (Q13) & $0.73(0.041)$ & 0.45 \\
\hline Feel that it was difficult to carry out (Q19) & $0.78(0.034)$ & 0.38 \\
\hline Interfered with social activities (Q20) & $0.78(0.034)$ & 0.38 \\
\hline Plan activities more carefully (Q27) & $0.82(0.028)$ & 0.31 \\
\hline Caused embarrassment (Q29) & $0.78(0.034)$ & 0.38 \\
\hline \multicolumn{3}{|l|}{ Energy (last 3 months) } \\
\hline Feel tired (Q12) & $0.81(0.029)$ & 0.34 \\
\hline Feel drowsy or sleepy during day (Q17) & $0.72(0.039)$ & 0.47 \\
\hline Feel sad, discouraged or hopeless (Q23) & $0.88(0.020)$ & 0.21 \\
\hline Feel down hearted and blue (Q24) & $0.88(0.019)$ & 0.21 \\
\hline Feel wiped out (Q25) & $0.86(0.022)$ & 0.25 \\
\hline Feel irritable (Q31) & $0.83(0.025)$ & 0.29 \\
\hline Feel weak as energy drained from her body (Q35) & $0.87(0.020)$ & 0.24 \\
\hline \multicolumn{3}{|l|}{ Control (last 3 months) } \\
\hline Feel that she is not in control of her life (Q14) & $0.79(0.033)$ & 0.37 \\
\hline Feel less productive (Q16) & $0.78(0.034)$ & 0.38 \\
\hline Concerned about her health (Q26) & $0.84(0.027)$ & 0.29 \\
\hline Feel uncertain about her future (Q30) & $0.77(0.035)$ & 0.39 \\
\hline Feel that she is not in control of her health (Q34) & $0.84(0.028)$ & 0.29 \\
\hline \multicolumn{3}{|l|}{ Self-conscious (last 3 months) } \\
\hline Feel self-conscious of weight gain (Q18) & $0.71(0.048)$ & 0.49 \\
\hline $\begin{array}{l}\text { Feel conscious about the size and appearance of her } \\
\text { stomach }(\mathrm{Q} 21)\end{array}$ & $0.80(0.041)$ & 0.35 \\
\hline $\begin{array}{l}\text { Affected the size of clothing she wears during her periods } \\
\text { (Q33) }\end{array}$ & $0.59(0.058)$ & 0.64 \\
\hline \multicolumn{3}{|l|}{ Sexual function (last 3 months) } \\
\hline Diminished sexual desire (Q36) & $0.90(0.031)$ & 0.17 \\
\hline Caused patient to avoid sexual relations (Q37) & $0.90(0.032)$ & 0.18 \\
\hline Covariance Severity - Concern & $0.91(0.018)$ & --------------- \\
\hline Covariance Severity - Activity & $0.79(0.036)$ & --------------- \\
\hline Covariance Severity - Energy & $0.78(0.034)$ & --------------- \\
\hline Covariance Severity - Control & $0.80(0.035)$ & -------------- \\
\hline Covariance Severity - Self-conscious & $0.81(0.043)$ & \\
\hline Covariance Severity - Sexual function & $0.65(0.050)$ & --------------- \\
\hline
\end{tabular}


Table 7. Test-retest of the UFS-QOL questionnaire at the study group $(n=20)$ UFS-QOL = Uterine Fibroid Symptom and Quality of Life; HRQL = health related quality of life.

\begin{tabular}{|c|c|c|c|c|}
\hline & Test & Retest & & \\
\hline UFS-QOL & \multicolumn{2}{|c|}{ Mean (standard deviation) } & $\begin{array}{c}\text { Mean } \\
\text { difference }\end{array}$ & P-value \\
\hline Symptom severity & 57.19 (19.35) & $52.03(32.81)$ & -5.16 & 0.453 \\
\hline Concern & $39.5(33.34)$ & $48.25(35.37)$ & +8.75 & 0.088 \\
\hline Activities & $54.8(27.79)$ & $61.79(30.35)$ & +6.96 & 0.270 \\
\hline Energy/mood & $54.64(32.36)$ & $54.11(33.83)$ & -0.53 & 0.929 \\
\hline Control & $53.5(27.29)$ & $60(32.16)$ & +6.5 & 0.223 \\
\hline Self-conscious & $50.83(31.75)$ & $53.33(32.82)$ & +2.5 & 0.746 \\
\hline Sexual function & $46.25(35.14)$ & $45(39.82)$ & -1.25 & 0.892 \\
\hline HRQL score & $\begin{array}{c}133.23 \\
(133.27)\end{array}$ & $\begin{array}{c}152.99 \\
(158.69)\end{array}$ & +19.77 & 0.452 \\
\hline
\end{tabular}

UFS-QOL = Uterine Fibroid Symptom and Quality of Life; HRQL = health related quality of life. 
Supplementary material 1 - UFS-QOL questionnaire after translation and cultural validation to the Brazilian Portuguese language

RUBRICA DA PACIENTE:

IDENTIDADE ou REGISTRO DA PACIENTE:

DATA:

\section{QUESTIONÁRIO SOBRE SINTOMAS DO LEIOMIOMA/MIOMA UTERINO E QUALIDADE DE VIDA}

\section{(UFS-QOL)}

Encontram-se listados, abaixo, sintomas experimentados por mulheres portadoras de mioma uterino. Avalie, por favor, a maneira como cada sintoma se relaciona com o mioma uterino ou seu ciclo menstrual. $\mathrm{O}$ objetivo de cada pergunta é saber o quanto cada um desses sintomas tem incomodado você nos últimos 3 meses.

Não há respostas certas ou erradas. Certifique-se, por favor, de responder cada pergunta assinalando (X) no quadrado mais apropriado. Se a pergunta não se aplicar a você, marque a resposta "nada" 


\begin{tabular}{|c|c|c|c|c|c|}
\hline $\begin{array}{l}\text { Durante os últimos } 3 \text { meses, diga o } \\
\text { quanto você ficou incomodada com... }\end{array}$ & Nada & $\begin{array}{l}\text { Muito } \\
\text { pouco }\end{array}$ & $\begin{array}{l}\text { Um } \\
\text { pouco }\end{array}$ & Muito & Muitissímo \\
\hline $\begin{array}{l}\text { 1. Sangramento intenso durante sua } \\
\text { menstruação }\end{array}$ & $\begin{array}{l}\square \\
\mathbf{1}\end{array}$ & $\begin{array}{l}\square \\
2\end{array}$ & $\begin{array}{l}\square \\
\mathbf{3}\end{array}$ & $\begin{array}{l}\square \\
4\end{array}$ & 5 \\
\hline
\end{tabular}

2. Eliminação de coágulos durante a menstruação

$\begin{array}{lllll}\square & \square & \square & \square & \square \\ \mathbf{1} & \mathbf{2} & \mathbf{3} & \mathbf{4} & \mathbf{5}\end{array}$

3. Variação na duração do seu ciclo menstrual quando comparada com seus ciclos anteriores

$\begin{array}{lllll}\square & \square & \square & \square & \square \\ \mathbf{1} & \mathbf{2} & \mathbf{3} & \mathbf{4} & \mathbf{5}\end{array}$

4. Variação no intervalo do seu ciclo menstrual quando comparada com seus ciclos anteriores

$\square$

$\begin{array}{llll}\square & \square & \square & \square \\ \mathbf{2} & \mathbf{3} & \mathbf{4} & \mathbf{5}\end{array}$

5. Sensação de aperto ou pressão na região do baixo ventre ("pé da barriga”)

$\begin{array}{lllll}\square & \square & \square & \square & \square \\ \mathbf{1} & \mathbf{2} & \mathbf{3} & \mathbf{4} & \mathbf{5}\end{array}$

6. Aumento da vontade de urinar durante o dia

$\begin{array}{lllll}\square & \square & \square & \square & \square \\ \mathbf{1} & \mathbf{2} & \mathbf{3} & \mathbf{4} & \mathbf{5}\end{array}$

7. Aumento da vontade de urinar durante a noite

$\begin{array}{lllll}\square & \square & \square & \square & \square \\ \mathbf{1} & \mathbf{2} & \mathbf{3} & \mathbf{4} & \mathbf{5}\end{array}$

8. Sensação de cansaço

$\square$

As próximas questões procuram saber sobre seus sentimentos e experiências em relação ao impacto do leiomioma uterino em sua vida. Considere, por favor, cada pergunta na medida em que ela se relaciona com suas experiências sobre esse assunto nos últimos 3 meses.

Não há respostas certas ou erradas. Certifique-se, por favor, de responder cada pergunta assinalando (X) no quadrado mais apropriado. Se a pergunta não se aplicar a você, marque a resposta "nunca" 


\begin{tabular}{c|c|c|c|c|c}
\hline $\begin{array}{c}\text { Durante os últimos 3 meses, com que } \\
\text { frequência seus sintomas relacionados } \\
\text { ao mioma uterino... }\end{array}$ & Nunca & $\begin{array}{c}\text { Poucas } \\
\text { vezes }\end{array}$ & $\begin{array}{c}\text { Algumas } \\
\text { vezes }\end{array}$ & $\begin{array}{c}\text { A } \\
\text { maior } \\
\text { parte } \\
\text { do } \\
\text { tempo }\end{array}$ & $\begin{array}{c}\text { O } \\
\text { tempo } \\
\text { todo }\end{array}$ \\
\hline
\end{tabular}

9. Fizeram com que você se sentisse ansiosa sobre a falta de previsão da data ou duração da menstruação?

1

$\mathbf{2}$

$\mathbf{3}$

4

5

10. Fizeram com que você se sentisse ansiosa em relação a viajar?

$\begin{array}{lllll}\square & \square & \square & \square & \square \\ \mathbf{1} & \mathbf{2} & \mathbf{3} & \mathbf{4} & \mathbf{5}\end{array}$

11. Interferiram em suas atividades físicas?

$\begin{array}{lllll}\square & \square & \square & \square & \square \\ \mathbf{1} & \mathbf{2} & \mathbf{3} & \mathbf{4} & \mathbf{5}\end{array}$

12. Fizeram com que você se sentisse cansada ou exausta?

13. Fizeram com que você diminuísse a quantidade de tempo que você usa em exercícios ou outras atividades físicas?

14. Fizeram com que você se sentisse como se não tivesse controle sobre sua vida?

15. Fizeram com que você se sentisse preocupada com possibilidade de manchar peças íntimas?

16. Fizeram com que você se sentisse menos produtiva em termos de trabalho?

17. Fizeram com que você se sentisse com sono ou tontura durante o dia?

18. Fizeram com que você tivesse a sensação de ganho de peso?

19. Fizeram com que você sentisse que estava difícil realizar suas atividades habituais?

1


20. Interferiram em suas atividades sociais?

$\begin{array}{lllll}\square & \square & \square & \square & \square \\ \mathbf{1} & \mathbf{2} & \mathbf{3} & \mathbf{4} & \mathbf{5}\end{array}$

21. Fizeram você perceber sobre o tamanho e a aparência da sua barriga?

$\begin{array}{lllll}\square & \square & \square & \square & \square \\ \mathbf{1} & \mathbf{2} & \mathbf{3} & \mathbf{4} & \mathbf{5}\end{array}$

22. Fizeram com que você se sentisse preocupada em manchar roupas de cama?

$\begin{array}{lllll}\square & \square & \square & \square & \square \\ \mathbf{1} & \mathbf{2} & \mathbf{3} & \mathbf{4} & \mathbf{5}\end{array}$

\begin{tabular}{c|c|c|c|c|c}
\hline $\begin{array}{c}\text { Durante os últimos 3 meses, com que } \\
\text { frequência seus sintomas relacionados } \\
\text { ao mioma uterino... }\end{array}$ & Nunca & $\begin{array}{c}\text { Poucas } \\
\text { vezes }\end{array}$ & $\begin{array}{c}\text { Algumas } \\
\text { vezes }\end{array}$ & $\begin{array}{c}\text { A } \\
\text { maior } \\
\text { parte } \\
\text { do } \\
\text { tempo }\end{array}$ & $\begin{array}{c}\text { O } \\
\text { tempo } \\
\text { todo }\end{array}$ \\
\hline
\end{tabular}

23. Fizeram com que você se sentisse triste, desanimada ou desesperada?

1

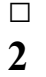

ㅁ

4

5

24. Fizeram com que você se sentisse deprimida ou abatida?

$\begin{array}{lllll}\square & \square & \square & \square & \square \\ \mathbf{1} & \mathbf{2} & \mathbf{3} & \mathbf{4} & \mathbf{5}\end{array}$

25. Fizeram com que você se sentisse extremamente cansada?

26. Fizeram com que você se sentisse preocupada ou ansiosa em relação à sua saúde?

27. Fizeram com que você planejasse suas atividades com mais cuidado?

28. Fizeram com que você se sentisse incomodada por sempre carregar absorventes, absorventes internos ou roupas extras para evitar “acidentes”?

29. Causaram-lhe constrangimento? 
30. Fizeram com que você sentisse incerteza em relação ao seu futuro?

$\begin{array}{lllll}\square & \square & \square & \square & \square \\ \mathbf{1} & \mathbf{2} & \mathbf{3} & \mathbf{4} & \mathbf{5}\end{array}$

31. Fizeram com que você se sentisse irritada?

$\begin{array}{lllll}\square & \square & \square & \square & \square \\ \mathbf{1} & \mathbf{2} & \mathbf{3} & \mathbf{4} & \mathbf{5}\end{array}$

32. Fizeram com que você se sentisse preocupada em relação a manchar a parte externa da roupa?

33. Afetaram o tamanho das roupas que você costuma usar durante seus ciclos menstruais?

1

$\square$

$\square$

4

$\mathbf{5}$

34. Fizeram com que você sentisse sem controle sobre sua saúde?

$\begin{array}{lllll}\square & \square & \square & \square & \square \\ \mathbf{1} & \mathbf{2} & \mathbf{3} & \mathbf{4} & \mathbf{5}\end{array}$

35. Fizeram com que você se sentisse fraca, como se a energia tivesse sido "sugada” do seu corpo?

36. Diminuíram seu desejo sexual (vontade de ter relação)?

$\begin{array}{lllll}\square & \square & \square & \square & \square \\ \mathbf{1} & \mathbf{2} & \mathbf{3} & \mathbf{4} & \mathbf{5}\end{array}$

37. Fizeram com que você evitasse ter relações sexuais?

\begin{tabular}{ll}
$\square$ & $\square$ \\
$\mathbf{1}$ & $\mathbf{2}$ \\
\hline
\end{tabular}




\section{Anexo VI - Retrotradução do questionário}

Patient signature:

Patient MRN:

Date:

\section{Uterine Fibroid Symptoms and Quality of Life Questionnaire (UFS-QOL)}

We have listed in the next lines, symptoms that are reported by women that present uterine fibroids. We would like to ask you to assess the way that each symptom relates with the uterine fibroid or your menstrual cycle. The aim of each question is to know how each of these symptoms have bothered you in the last three months.

There is no right or wrong answers. Please, mark the answer that you feel it is most appropriate, signaling $(\mathrm{X})$ in the square. If the question does not apply to you, please mark the option "Nothing"

\section{During the last 3 months, tell us how concerned were you by...}

1. Heavy bleeding during your menstrual period

2. Passing blood clots during your menstrual period

3. Variation at the duration of your menstrual period when compared to your previous one

4. Variation in the length of your menstrual cycle when compared to your previous one

5. Feeling tightness or pressure in the low part of the abdômen (below the belly button)

6. Increased urination frequency during daytime$$
1
$$

1

\begin{tabular}{|l|l|l|l}
$\begin{array}{l}\text { A } \\
\text { little } \\
\text { bit }\end{array}$ & Somewhat & A lot & Extremely \\
\hline
\end{tabular}

1

Nothing

(a)

23

$\begin{array}{ll}\square & \square \\ \mathbf{4} & \mathbf{5}\end{array}$

\section{5}

1

$\begin{array}{llll}\square & \square & \square & \square \\ \mathbf{2} & \mathbf{3} & \mathbf{4} & \mathbf{5}\end{array}$

$\square$

$\begin{array}{ll}\square & \square \\ \mathbf{4} & \mathbf{5}\end{array}$

$\begin{array}{ll}\square & \square \\ \mathbf{2} & \mathbf{3}\end{array}$

$\begin{array}{ll}\square & \square \\ \mathbf{4} & \mathbf{5}\end{array}$

7. Increased nighttime urination

8. Feeling tired

\section{$\square$}

2 $\mathbf{3}$

$\begin{array}{ll}\square & \square \\ \mathbf{4} & \mathbf{5}\end{array}$

\begin{tabular}{lll}
$\square$ & $\square$ & $\square$ \\
$\mathbf{1}$ & $\mathbf{2}$ & $\mathbf{3}$ \\
\hline
\end{tabular}

$\begin{array}{ll}\square & \square \\ \mathbf{4} & \mathbf{5}\end{array}$ 
The next questions are talking about your feelings and experiences with regard to the impact of the uterine fibroid in your life. Please, consider that each question is asking how this subject impacted your life in the last three months.

There is no right or wrong answers. Please, mark the answer that you feel it is most appropriate, signaling $(\mathrm{X})$ in the square. If the question does not apply to you, please mark the option "Never"

\section{During the last 3 months, how often the symptoms related with uterine fibroids... \\ 9. Made you feel anxious about the imprevisibility of the last menstrual period or menstrual duration? \\ 10. Made you feel anxious with regard to travelling?}

11. Interfered in their physical activities?

12.Made you feel tired or exhausted?

13. Made you decrease the amount of time that you use in exercises or other physical activities?

14. Made you feel that you did not have any control about your life?

15. Made you feel worried with the possibility of soiling underwears?

16. Made you feel less productive with regard to work?

17. Made you feel sleepy or dizzy during daytime?

18. Made you feel that you had the sensation of weight gain?

19. Made you feel that it was difficult to perform your routine activities?

\begin{tabular}{|l|l|l|l|l} 
Never & $\begin{array}{l}\text { Few } \\
\text { times }\end{array}$ & $\begin{array}{l}\text { Some } \\
\text { times }\end{array}$ & $\begin{array}{l}\text { Most of } \\
\text { the } \\
\text { time }\end{array}$ & $\begin{array}{l}\text { All of } \\
\text { the } \\
\text { time }\end{array}$ \\
\hline
\end{tabular}

$\square$

12

2

$\square$

4

5

$\begin{array}{lllll}\square & \square & \square & \square & \square \\ \mathbf{1} & \mathbf{2} & \mathbf{3} & \mathbf{4} & \mathbf{5}\end{array}$

$\square$

4

$\square$

5


20. Interfered in your social activities?

$\begin{array}{lllll}\square & \square & \square & \square & \square \\ \mathbf{1} & \mathbf{2} & \mathbf{3} & \mathbf{4} & \mathbf{5}\end{array}$

21. Made you noticed about the size and appearance of your stomach?

$\square$

$\begin{array}{ll}\square & \square \\ 4 & 5\end{array}$

22. Made you feel worried about soiling bed linen?

$\begin{array}{lllll}\square & \square & \square & \square & \square \\ \mathbf{1} & \mathbf{2} & \mathbf{3} & \mathbf{4} & \mathbf{5}\end{array}$

\begin{tabular}{l}
$\begin{array}{l}\text { During the last } 3 \text { months, how often the } \\
\text { symptoms related with uterine } \\
\text { fibroids... }\end{array}$ \\
\hline
\end{tabular}

23. Made you feel sad, unhappy or desperate?

1

1

2

$\square$

$\begin{array}{ll}\square & \square \\ \mathbf{4} & \mathbf{5}\end{array}$

24. Made you feel downhearted or blue?

$\begin{array}{lllll}\square & \square & \square & \square & \square \\ \mathbf{1} & \mathbf{2} & \mathbf{3} & \mathbf{4} & \mathbf{5}\end{array}$

25. Made you feel extremely tired?

$\begin{array}{lllll}\square & \square & \square & \square & \square \\ \mathbf{1} & \mathbf{2} & \mathbf{3} & \mathbf{4} & \mathbf{5}\end{array}$

26. Made you feel worried or anxious with regard to your health?

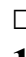

1

$\square$

$\square$

$\square$

5

27. Made you plan more carefully your activities?

$\begin{array}{lllll}\square & \square & \square & \square & \square \\ \mathbf{1} & \mathbf{2} & \mathbf{3} & \mathbf{4} & \mathbf{5}\end{array}$

28. Made you feel bothered for always carry tampons, OBs, extra clothes in order to avoid "acidentes”?

29. Caused you embarassment?

30. Made you feel uncertain with regard to your future?

31. Made you feel irritated? 
33. Affected the size of clothes that you use to wear during your menstrual cycles?

1

2

$\square$

4

5

34. Made you feel without controle over your health?

$\begin{array}{lllll}\square & \square & \square & \square & \square \\ \mathbf{1} & \mathbf{2} & \mathbf{3} & \mathbf{4} & \mathbf{5}\end{array}$

35. Made you feel weak, like the energy of your body had been drown up?

$\begin{array}{lllll}\square & \square & \square & \square & \square \\ \mathbf{1} & \mathbf{2} & \mathbf{3} & \mathbf{4} & \mathbf{5}\end{array}$

36. Decreased your sexual drive (express desire for having sexual relations)?

$\begin{array}{lllll}\square & \square & \square & \square & \square \\ \mathbf{1} & \mathbf{2} & \mathbf{3} & \mathbf{4} & \mathbf{5}\end{array}$

37. Made you avoid having sexual $\square$

\begin{tabular}{|c|c|}
\hline$\square$ & $\square$ \\
\hline 3 & 4 \\
\hline
\end{tabular}

